
\title{
$\mathrm{UNLV} \mid \underset{\text { LIBRARIES }}{\mathrm{UNIVRSTY}}$
}

UNLV Retrospective Theses \& Dissertations

$1-1-2006$

\section{Acculturation and sexuality: Investigating gender differences in erotic plasticity}

Lorraine Benuto

University of Nevada, Las Vegas

Follow this and additional works at: https://digitalscholarship.unlv.edu/rtds

\section{Repository Citation}

Benuto, Lorraine, "Acculturation and sexuality: Investigating gender differences in erotic plasticity" (2006). UNLV Retrospective Theses \& Dissertations. 2092.

http://dx.doi.org/10.25669/7g7y-jrs0

This Thesis is protected by copyright and/or related rights. It has been brought to you by Digital Scholarship@UNLV with permission from the rights-holder(s). You are free to use this Thesis in any way that is permitted by the copyright and related rights legislation that applies to your use. For other uses you need to obtain permission from the rights-holder(s) directly, unless additional rights are indicated by a Creative Commons license in the record and/ or on the work itself.

This Thesis has been accepted for inclusion in UNLV Retrospective Theses \& Dissertations by an authorized administrator of Digital Scholarship@UNLV. For more information, please contact digitalscholarship@unlv.edu. 
ACCULTURATION AND SEXUALITY: INVESTIGATING

\title{
GENDER DIFFERENCES IN
}

EROTIC PLASTICITY

by

\author{
Lorraine Benuto \\ Bachelor of Arts \\ Dominican University \\ 2003
}
A thesis submitted in partial fulfillment of the requirements for the

\section{Master of Arts Degree in Psychology \\ Department of Psychology \\ College of Liberal Arts}

\author{
Graduate College \\ University of Nevada, Las Vegas \\ December 2006
}


UMI Number: 1443740

Copyright 2007 by

Benuto, Lorraine

All rights reserved.

\title{
INFORMATION TO USERS
}

The quality of this reproduction is dependent upon the quality of the copy submitted. Broken or indistinct print, colored or poor quality illustrations and photographs, print bleed-through, substandard margins, and improper alignment can adversely affect reproduction.

In the unlikely event that the author did not send a complete manuscript and there are missing pages, these will be noted. Also, if unauthorized copyright material had to be removed, a note will indicate the deletion.

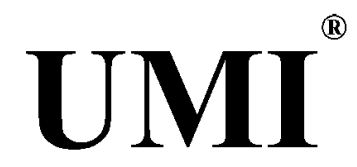

UMI Microform 1443740

Copyright 2007 by ProQuest Information and Learning Company.

All rights reserved. This microform edition is protected against

unauthorized copying under Title 17, United States Code.

\author{
ProQuest Information and Learning Company \\ 300 North Zeeb Road \\ P.O. Box 1346 \\ Ann Arbor, Ml 48106-1346
}




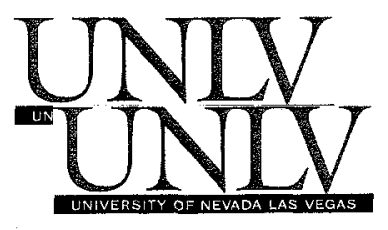

\section{Thesis Approval}

The Graduate College

University of Nevada, Las Vegas

September 25 $20 \lcm{06}$

The Thesis prepared by

Lorraine Benuto

Entitled

Acculturation and sexuality: Investigating Gender Differences

in Erotic Plasticity

is approved in partial fulfillment of the requirements for the degree of

Master of Arts in Psychology

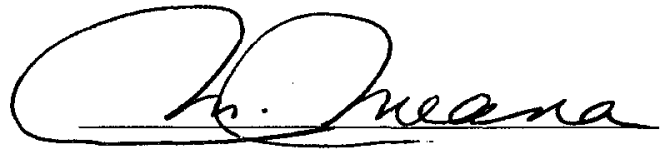

Examination Committee Chair

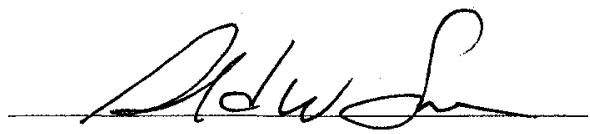

Dean of the Graduate College

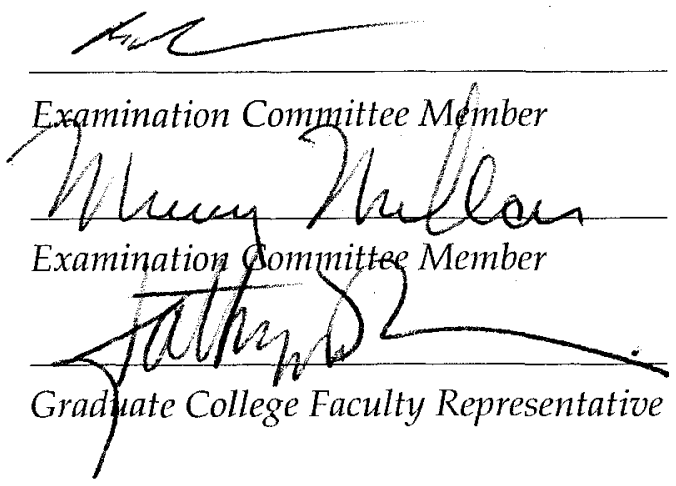


ABSTRACT

Acculturation and Sexuality: Gender Differences in Erotic Plasticity

\author{
by \\ Lorraine Benuto, B.A. \\ Dr. Marta Meana, Examination Committee Chair \\ Professor of Psychology \\ University of Nevada, Las Vegas
}

Baumeister's theory on female erotic plasticity is supported by a significant body of data that suggests that female sexuality is more malleable than male sexuality and thus more greatly influenced by external factors. Seeking to test Baumeister's theory, this study examined the potential differential impact of the acculturation process on the sexual attitudes and experiences of 188 college men and 310 college women. Sexual attitudes and experiences were measured using the Derogatis Sexual Functioning Inventory and acculturation level was determined using the General Ethnicity Questionnaire. Betweengender analyses revealed that the acculturation process did not have more of a liberalizing effect on the sexual attitudes and experiences of women than on those of men. This finding is inconsistent with Baumeister's theory. Ethnic and acculturation level main effects were identified for sexual experiences and attitudes and a gender main effect was identified for sexual attitudes only. Investigating ethnic, gender, and acculturative differences not only adds to the sparse body of literature on the eudeamonic sexuality of 
ethnic minorities but may also be useful in developing culturally competent and genderspecific interventions for sex therapy. 


\section{TABLE OF CONTENT}

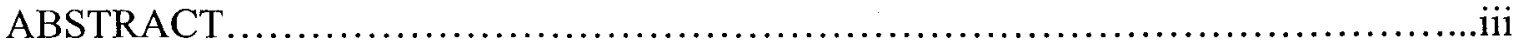

LIST OF TABLES ...............................................................

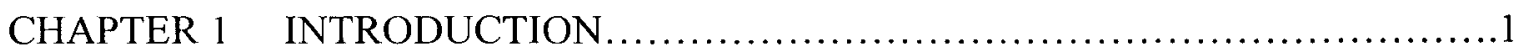

CHAPTER 2 REVIEW OF RELATED LITERATURE REVIEW $\ldots \ldots \ldots \ldots \ldots \ldots \ldots$

Female Erotic Plasticity.....................................................

Intra-Individual Variation in Sexual Attitudes and Behaviors......................4

Sociocultural Variation in Sexual Attitudes and Behaviors.........................8

Attitude-Behavior Inconsistency in Sexual Behavior and Attitudes................12

Explanations and Controversy .............................................. 15

Ethnocultural Differences in Sexual Attitudes and Behaviors........................16

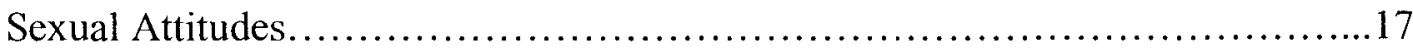

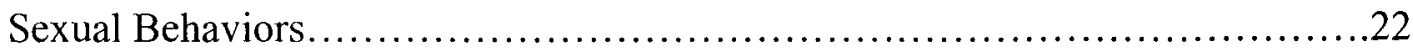

Acculturation and Sexual Attitudes and Behaviors.................................28

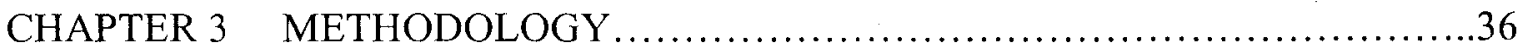

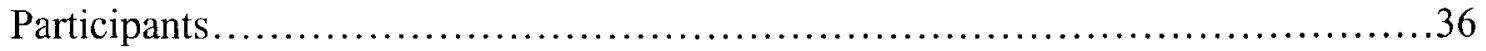

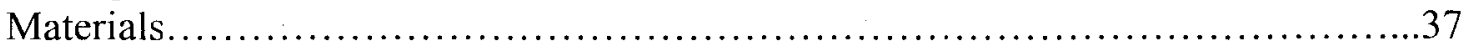

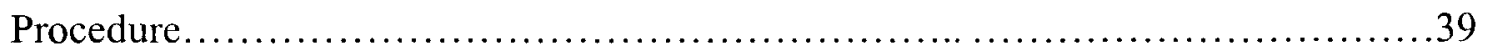

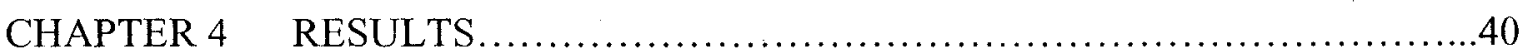

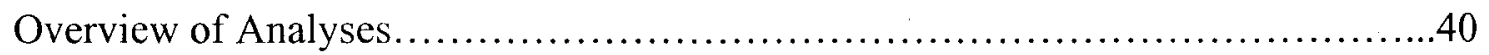

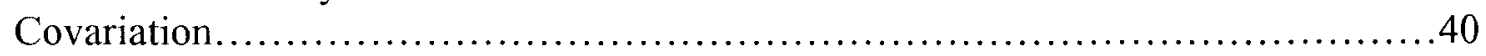

Characteristics of the Distribution of Dependent Variables...........................41

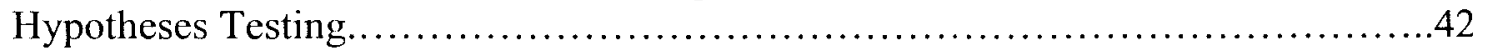

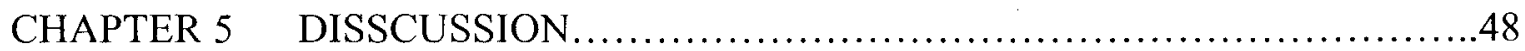

Gender Differences............................................................... 48

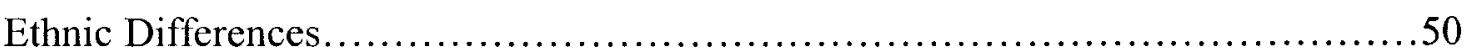

Acculturative Differences...................................................52

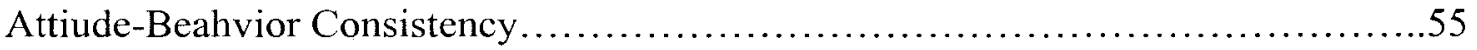

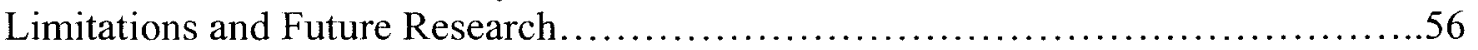

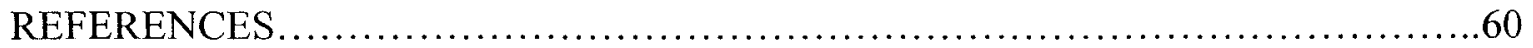




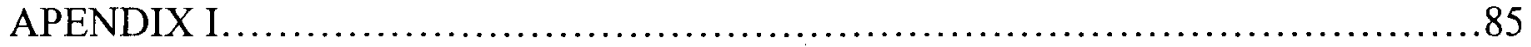

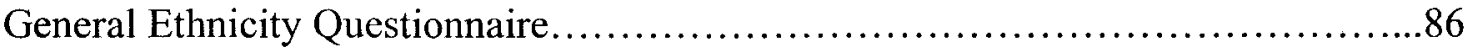

Deragatis Sexual Functioning Inventory ......................................94

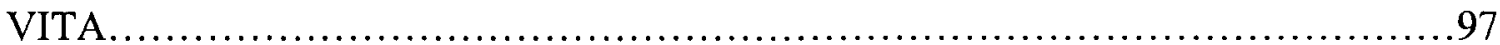




\section{LIST OF TABLES}

Table 1 Demographic Characteristics of the Participants........................... 71

Table 2 Means and Standard Deviations for Sexual Attitudes and Sexual Experience................................................73

Table 3 Analysis of Covariance of Sexual Attitudes as a Function of Gender, With Age as a Covariate..............................74

Table 4 Analysis of Covariance of Sexual Experience as a Function of Gender, Age as a Covariate.

Table 5 Analysis of Covariance of Sexual Attitudes as a Function of Ethnicity (Minority vs. Majority),

With Age as a Covariate

Table 6 Analysis of Covariance of Sexual Experiences as a Function of Ethnicity (Minority vs. Majority), With Age as a Covariate.

Table 7 Analysis of Covariance of Sexual Attitudes as a Function of Ethnicity (African American vs.

Asian American, vs. Eureopean American vs. Latino), With Age as a Covariate.

Table 8 Analysis of Covariance of Sexual Experiences as a Function of Ethnicity (African American vs. Asian American, vs. European American, vs. Latino), With Age as a Covariate

Table 9 Analysis of Covariance of Sexual Attitudes as a Function of Gender, Ethnicity (excluding European

Americans), and Acculturation, With Age as a Covariate.

Table 10 Analysis of Covariance of Sexual Experience as a

Function of Gender, Ethnicity (excluding European

Americans), and Acculturation, With Age as a Covariate

Table 11 Intercorrelations for Scores on Acculturation, Sexual Attitudes and Sexual Attitudes as a Function of Gender.

Table 12 Hierarchical Moderated Multiple Regression Analyses for Effects of Gender, Acculturation and their Interaction Term on Sexual Attitudes

Table 13 Hierarchical Moderated Multiple Regression Analyses for Effects of Gender, Acculturation and their Interaction. 


\section{CHAPTER 1}

\section{INTRODUCTION}

Research has demonstrated that female sexuality is more influenced by external factors than male sexuality (Ford \& Norris, 1993; Kinsey, Pomeroy, Martin, \& Gebhard, 1953; Miller \& Moore, 1990; Murphy, 1992; Weis, Rabinowitz, \& Ruckstuhl, 1992;), prompting Baumeister (2000) to propose the theory of female erotic plasticity, suggesting that women have higher degrees of erotic flexibility than men. Erotic plasticity refers to the extent to which a person's sexual attitudes, behaviors, and desires can be shaped and altered by cultural and social factors. Baumeister (2000) derives three major predictions from the female erotic plasticity hypothesis: that female sexuality should be characterized by greater intra-individual variation, greater susceptibility to socio-cultural factors, and lower attitude-behavior consistency when compared to men.

Intra-individual variability refers to the variation across an individual's sexual history. Within this prediction, Baumeister (2000) postulates that if erotic plasticity is greater among women, then one can expect women to show more variation across their individual sexual histories then men. Therefore, women will tend to exhibit changes in their sexuality over time more so than their male counterparts. This idea has been thoroughly supported in the literature (Adams \& Turner, 1985; Dixon, 1984).

The second prediction discussed by Baumeister (2000) involves the impact of sociocultural factors on sexuality. Because sociocultural factors are thought to carry an 
impact on sexuality, Baumeister (2000) predicts that women will be more influenced by sociocultural factors as a result of their high degree of erotic plasticity. The literature has demonstrated that sociocultural factors have indeed been found to have a greater impact on female sexuality when compared to male sexuality (Christensen \& Carpenter, 1962; Barry \& Schiegel, 1984; Ford \& Norris, 1993). Culture, acculturation, education, religion, and peers/parents are all amongst the sociocultural factors discussed by Baumeister. While there is an abundance of literature demonstrating that education (Wilson, 1975; Weis, Rabinowitz, \& Ruckstuhl, 1992), religion (Harrison, Bennett, Globetti, \& Alsikafi, 1974, Earle \& Perricone, 1986; Murphy, 1992), and peers/parents (Sack, Keller, \& Hinkie, 1984; Miller \& Moore, 1990; Mirande, 1968) are influential sociocultural factors affecting sexuality, there seems to be a paucity of research on the relationship between culture/acculturation and sexuality.

The acculturation process is a complex and intriguing process that involves adopting or acquiring the language, customs, values, habits, beliefs, attitudes, behaviors and lifestyles of the dominant culture or non-native society (Cortes, Rogler, \& Malgady, 1994). Clearly sexual attitudes fall under the "attitude" portion of the acculturation process and if an individual is acculturating he/she is likely to acquire the sexual attitudes that are reflected by the dominant culture.

Based on Baumeister's theory it seems logical that the acculturation process will have a greater impact on the sexual attitudes of women than those of men. Perhaps this is a result of male sexuality being shaped by early experiences, indicating that men may be more influenced by their culture of origin to which they are exposed early on. Conversely, the literature has demonstrated that women are more malleable in their 
sexuality (Baumeister, 2000) suggesting that they may be more receptive to cultural influences to which they are exposed to later in life.

The last prediction that Baumeister (2000) makes in conjunction with the erotic plasticity hypothesis is that attitude-behavior inconsistency will be greater among women. Many research studies have demonstrated greater attitude-behavior inconsistency in regards to sexuality for women than men (Roebuck \& McGee, 1997; Herold \& Mewhinney, 1993; Beck, Bozman, \& Qualtrough, 1991). Baumeister (2000) suggests that if female sexuality is more pliable than male sexuality to the pressures of situational forces, women should be more likely to engage in activities that go against their general attitudes, resulting in greater attitude-behavior inconsistency. That is, while a woman may state that she believes in something, her behavior may not align with her stated attitude. Coinciding with this idea is the concept that while women may express liberal attitudes in terms of sexuality, their attitudes may not be expressed through their behaviors. This idea falls in line with the research that has demonstrated a greater degree of attitude-behavior inconsistency among women.

The present study's hypotheses were based upon the predictions derived primarily from the theory of female erotic plasticity and also from the existing literature on ethnicity and sexuality. An elaboration of existing research and this study's hypotheses will follow, however the main purpose of this study was to determine if a differential gender effect of acculturation on sexual attitudes and behavior exists. A secondary idea that was also tested was whether women indeed exhibited a lower attitude-behavior consistency than men within this multicultural sample. Support was not found for either of the hypotheses described above. 


\section{CHAPTER 2}

\section{LITERATURE REVIEW}

In the following section, literature relevant to the current proposal is reviewed. These sections include: 1)Female Erotic Plasticity, 2) Ethnocultural Differences in Sexual Attitudes and Behaviors, 3) Acculturation and Sexual Attitudes and Behaviors.

\section{Female Erotic Plasticity}

A review of the literature on female sexuality indicates that contextual factors may influence female sexuality more heavily than male sexuality. In a critical review of said literature, Baumeister (2000) proposed the theory of female erotic plasticity, hypothesizing that the female sex drive is more flexible and responsive to contextual factors and thus more erotically plastic, whereas male sexuality seems to be determined early in childhood or before and is less prone to change throughout the lifespan. From his female erotic plasticity theory, Baumeister (2000) derives three empirical predictions for which he finds support in the empirical literature. The three predictions are that females, if indeed more erotically plastic, should exhibit greater intraindividual variation in sexual behavior, more cross-cultural variation, and less attitude-behavior consistency than men.

\section{Intra-Individual Variation in Sexual Attitudes and Behaviors}

In terms of the intraindividual variability hypothesis, Baumeister (2000) predicts that if women are more erotically plastic than men, they should exhibit greater variation 
across their individual sexual histories. He predicts that women are more likely to experience shifts and changes in their sexual desires and behaviors as they move through changing sexual situations and circumstances throughout their lives. Conversely, men are hypothesized as being less flexible in their sexuality and more likely to reflect sexual patterns that will remain more stable and constant across different situations and time.

The literature provides support for the intraindividual variation prediction in studies examining degree of sexual activity (Adams \& Turner, 1985; Kinsey, Pomeroy, \& Martin, 1948), amount of dating experience (Harrison, Bennett, Globetti, \& Alsikafi, 1974), and sexual orientation (Dixon, 1984; Fang, 1976; McCauley \& Ehrhardt, 1980). Studies examining degree of sexual activity have demonstrated that women tend to show patterns of considerable variance in terms of how much sexual activity they are engaging in, when compared to men. Research has shown that women may go through bouts of having a great deal of sex followed by a period of dormant sexual activity, while males tend to maintain a more consistent frequency of sexual activity, be it through masturbation or sexual encounters (Kinsey, Pomeroy, Martin, \& Gebhard, 1953).

Adams and Turner (1985) also found a greater intraindividual variability for women when examining the current and past sexual practices of a sample of older adults. The sample consisted of 60 women and 40 men, aged 60 to 85 . Contrary to most research studies examining the sexual activity of older adults, they specifically looked for signs of increases in sexual practices and sexual satisfaction. Supporting the intraindividual variability prediction, the small subset of participants found to have experienced increases in sexual activity and satisfaction consisted mostly of women. Within the subsample of participants who had experienced increases in sexual activity, women were 
also found to have significant increases in masturbation over time, whereas men were found to have nonsignificant decreases in masturbation over time. Male masturbatory patterns were found be more consistent and constant over the life course, whereas women who reported masturbation in younger adulthood were found to show decreases in masturbation in later life (Adams \& Turner, 1985), indicating a more constant pattern for the men and a more variable pattern for the women.

Also supporting the idea that female sexuality varies more across time than male sexuality, Harrison, Bennett, Globetti, and Alsikafi, (1974) examined the sexual attitudes of 132 adolescents who were dating. Results indicated that sexual standards of girls changed in a more permissive direction as they accrued dating experience. These results were not found among the male participants of this study, indicating again that women tend to vary across time in terms of their sexuality more so than men. Earle and Perricone (1986) compared freshman and senior sexual attitudes at a small religious college and noted that female sexual attitudes changed more during the course of their college careers than did male sexual attitudes.

An additional, more dramatic indication of intraindividual variability concerns sexual orientation and same-gender sexual activity. Research has indicated that lesbians are more likely to have had heterosexual intercourse than gay males. Supporting this idea, McCauley and Ehrhardt (1980) examined sexual behavior in female transsexuals and lesbians. Subjects consisted of 30 participants ( 15 lesbian and 15 female-to-male transsexuals). Specifically, half the lesbian women in this study were found to have had heterosexual experiences prior to commencing homosexual activity. Results indicated that heterosexual experiences typically occurred up until the age of 20 . The female-to- 
male transsexuals in this study also reported similar results although they typically reported having their first sexual relationship with a woman in early or middle adolescence. These results support the notion that lesbian women are likely to experience both same-gender and opposite-gender sexual activity.

While the above study only included females, more recent research has included both men and women. Savin-Williams (1990) conducted a study on gay and lesbian adolescents and found that $80 \%$ of lesbian women had had heterosexual intercourse compared with only $50 \%$ of gay males. Further supporting this finding, Whisman (1996) found that $82 \%$ of the lesbians included in his sample had had sex with a member of the opposite gender and $72 \%$ of these women stated that they found this experience meaningful. Conversely, only $64 \%$ of the gay males in Whisman's sample reported having had sex with a woman and only $45 \%$ of these men reported that the experience was meaningful. This data again suggests that women may be more likely than men to have sexual relationships that fall outside of their primary sexual orientation and are more likely to find these relationships meaningful. These findings add support to the idea that female sexual behavior tends to vary more than male sexual behavior.

While the studies discussed above only included homosexual participants, research has also shown that heterosexual women are more likely to engage in samegender sexual activity than are heterosexual men. Fang (1976) noted that women often engage in same-gender sexual activity in swinging situations far more than their male counterparts. She concluded that while women in swinging relationships often begin having sex with other women to please their husbands or to be sociable, they often come to enjoy this activity. Dixon (1984) conducted a study consisting of 50 female volunteers 
aged 32-60 who were married, partaking in swinging, enjoying sex with males, and before the age of 30 had had no previous attraction to females. Results of this study yielded that $60 \%$ of the subjects reported having preadolescent crushes on males and none reported having had a crush on a female during preadolescence or adolescence, indicating a strong heterosexual orientation. The women in this study began engaging in same-gender sexual activity at the mean age of 37 and at the time of the study all participants identified themselves as bisexual. As in Fang's (1976) study, all subjects reported enjoying participating in same-gender sexual activity. The results of this study and the postulations made by Fang (1976) all support the notion that women vary more than men in terms of their sexuality, specifically within the context of shifting sexual orientation or simply being willing to and enjoying sex across these orientation categories. The results of a number of studies on sexual activity and attitudes, as well as sexual orientation, provide support for the idea of women's greater intraindividual variability in terms of their sexuality and that they are, therefore, erotically plastic.

\section{Sociocultural Variation in Sexual Attitudes and Behaviors}

Baumeister's (2000) second prediction, emerging from his theory of erotic plasticity is that women will display greater variation in sexual attitudes and behaviors across cultures or social circumstances that constitute sub-cultures. He also postulates that sociocultural variables will be better at predicting the sexual responses of women than those of men and that they will carry heavier influences on female sexuality. Research studies demonstrating that education (Wilson, 1975; Weis, Rabinowitz, \& Ruckstuhl, 1992), religion (Harrison, Bennett, Globetti, \& Alsikafi, 1974, Earle \& Perricone, 1986; Murphy, 1992), and peers/parents (Sack, Keller, \& Hinkie, 1984; Miller 
\& Moore, 1990; Mirande, 1968) are influential sociocultural factors affecting sexuality are abundant in the literature. While there is little research demonstrating that variables such as culture and acculturation have a greater impact upon female sexuality when compared to male sexuality, some minimal research does exist (e.g., Barry \& Schlegel, 1984; Christensen \& Carpenter, 1962; Ford \& Norris, 1993).

There is some support for the greater effects of education on female sexuality than on male sexuality. For example, Wilson (1975) explored the results of a national probability sample consisting of 2,486 adults across 48 contiguous states in the U.S. Participants were asked whether or not they believed that there is a great difference between what people do and what they would like to do when it comes to sex. Females with less education were more likely to endorse a difference than more educated females. Once more, educational differences were not found among men. Higher levels of education were also associated with postponement of first sex, and again these delays seem to have affected women more than men. Specifically, $19 \%$ of the least educated men had never engaged in sexual behavior at age 21 whereas $25 \%$ of the most educated men had never engaged in sexual behavior at age 21 (only a $6 \%$ difference). Conversely, $18 \%$ of the least educated women had never engaged in sexual behavior at age 21 whereas $43 \%$ of the most educated women had never engaged in sexual behavior at age 21 , resulting in a large difference of 25 percentage points.

Also supporting the differential impact of education on women and men was Weis, Rabinowitz, and Ruckstuhl's (1992) study on 172 university students enrolled in a sexuality course. Subjects were administered questionnaires on the first and last day of class. Results from this study indicated that while sexual attitudes became more 
permissive during the course, behavior did not significantly change. Changes in attitudes were, however, greater in female subjects, supporting the notion that sociocultural factors such as education influence female sexuality more so than male sexuality.

Research examining the relationship between religiosity and sexuality also offers support for Baumeister's prediction involving sociocultural factors. Religious beliefs seem to have a stronger inhibitory effect on female sexuality when compared to male sexuality. Results from the Adams and Turner (1985) study indicated that church attendance strongly predicted frequency of masturbation for women but not for men. The more religiously observant the woman, the lower the frequency of masturbation. Consistent with the findings discussed above, Earle and Perricone (1986) sampled students at a small religious college over the course of 11 years. Results from their study indicated that individuals who were more religious possessed less sexually permissive attitudes. This finding was true of both men and women. However, results from this study also indicated that socioeconomic status was correlated with sexually permissive attitudes for women only.

As a corollary to these findings on the differential impact of religion on male and female sexuality, Murphy (1992) found that male Catholic clergy were less likely to fulfill their vows of celibacy than were female Catholic clergy. Based on these findings it seems that women are more apt to conform to nonpermissive standards in a religious context. This suggests that sociocultural factors (such as religiosity) may have a greater impact on female sexuality and, again, indicates that women may indeed be more erotically plastic than men. 
Additional sociocultural factors that have been shown to have effects on sexuality are peers and parents. Mirande (1968) found results supporting the idea that peers do influence sexuality. In his sample of 93 undergraduates, he found that the sexual behaviors of the students were consistent with the standards and behaviors of their peer groups. More importantly, though, he found a significant relationship between peer group approval and sexual activity for women, but not for men. Results indicated that over half the women with sexual experience had peers who encouraged sexual activity, whereas almost all of women who were virgins had no friends who encouraged sexual activity. Furthermore, the correlation between having sexual experiences and having friends who also had sexual experience was significant for the women surveyed but not for the men.

Over 15 years later, Sack, Keller, and Hinkle (1984) conducted a study examining the effects of peer group influences on the sexual experience of 467 students. They found that number of sexually active friends did predict whether or not the men in this study engaged in premarital sex, however, the approval from friends for engaging in premarital sex was not related to their premarital sexual behavior. For women, on the other hand, both number of sexually active friends and degree of approval from friends for engaging in premarital sex were related to having premarital sexual behavior.

Parents have also been hypothesized to carry more influence on the sexual behavior of their daughters than their sons (Miller \& Moore 1990). For example, Newcomer \& Udry (1987) found that living with a single parent was related to an earlier loss of virginity for girls, but not for boys. Permissive sexuality among girls has been found to be related closely to a myriad of variables. Having older parents, parents who married at an earlier age, parents who are divorced, premarital pregnancy by mother, and 
mothers with permissive sexual attitudes have been found to be related to permissive sexuality more so for girls than for boys (Thorton \& Camburn, 1987).

Perhaps the least amount of research available to support Baumeister's second prediction is in the area of culture/ethnicity and acculturation. A couple of studies have found that women vary more than men in terms of premarital sex across cultures (Christensen \& Carpenter, 1962), as well as on other measures of sexual behavior (Barry \& Schiegel, 1984). The paucity of studies in this regard, however, makes conclusions more tentative. In terms of acculturation, Ford and Norris (1993) assessed the acculturation level of Hispanic immigrants and found that degree of acculturation was positively significantly correlated with various sexual practices in women only.

Although there is an abundance of literature that supports the idea that sociocultural factors tend to impact female sexuality more heavily than male sexuality, the research has focused on education, religion, peer and family pressure, and socioeconomic status. Clearly the area most lacking in empirical support is in the realm of culture, ethnicity, and acculturation. The most probable reason for this lack of support is the overall paucity of research on culture, ethnicity, and acculturation in general and their relationship to sexuality, in particular. Research on the sexual attitudes and behaviors of different cultures and ethnicities in this country is sorely lacking. Specifically, Lewis (2004) noted that most of the research on the sexuality of ethnic minorities is focused on preventative sexual health.

Attitude-Behavior Inconsistency in Sexual Behavior and Attitudes

The third prediction of the female erotic plasticity theory is that women will exhibit lower attitude-behavior consistency in regards to sexuality when compared to 
men (Baumeister, 2000). One might expect that if a woman's behavior is more flexible and responsive to situational forces, she is more likely to do things that go against her general attitudes. Because men are more rigid in terms of their sexuality, the prediction would be for greater attitude-behavior consistency in men.

Roebuck and McGee's (1977) study of 242 African American high school females aged 15 to 21 indicated that while most girls reported having conservative attitudes towards petting and sexual intercourse, these attitudes were not evident in their behavior. Christensen and Carpenter (1962) also found results indicating attitudebehavior inconsistency for women, as two thirds of the women in their sample had engaged in premarital sex against their personal values. Similarly, Antonovsky, Shoham, Kavenock, Mordan, and Lancer's (1978) study with 305 Israeli girls aged 14 to 18 indicated that one third of the girls who had experienced sexual intercourse reported that remaining a virgin until marriage was an important value. This suggests that, even though these participants disapproved of engaging in premarital sex, they continued doing so, resulting in an attitude-behavior inconsistency. While the above studies only included females in their sample, Croake and James (1973) included both females and males in their sample of 536 college undergraduates. Their goal was to assess sexual attitudes at two different time periods (1968 and 1972) in an attempt to demonstrate that students surveyed at the later date possessed more liberal attitudes towards premarital sexual behavior. What they found was that a higher percentage of women than men were engaging in sexual intercourse while disapproving of this behavior at both time periods.

Research studies have also found that women often engage in sexual behavior even though they lack the desire (Beck, Bozman, \& Qualtrough, 1991; O'Sullivan \& 
Allgeir, 1998). Beck, Bozman, and Qualtrough (1991) conducted a study consisting of 144 college students in an attempt to study the experience of sexual desire. Eighty-two percent of all females who participated in the study reported having engaged in sexual activity without desire, compared with only $60 \%$ of men. These results demonstrate attitude-behavior inconsistency for both men and women, although clearly the difference is greater for women.

Further supporting Baumeister's third prediction, Herold and Mewhinney (1993) found that women reported stronger intentions than men to use condoms during casual sex but actual condom use did not vary by gender. In addition, while only $28 \%$ of the women going to a singles bar reported anticipating casual sex, $59 \%$ actually engaged in casual sex, whereas $68 \%$ of the men reported anticipating casual sex and $80 \%$ actually had sex. The discrepancy is clearly larger for the women (31\% vs. $12 \%)$.

An additional form of attitude-behavior inconsistency manifests itself in the area of sexual orientation. Bell and Weinberg (1978) reported that lesbians in their sample were more likely to try ignoring their homosexual feelings and attempt to act in a heterosexual way, than were gay males. More recently, Golden (1987) found that some women identified as lesbian despite the fact that they reported having had engaged in heterosexual relationships exclusively. This attitude-behavior inconsistency also went the other way, in that women identified themselves as heterosexual despite only having engaged in sexual relationships with other women. No such results have been reported for men.

In summary, a substantial body of research supports Baumeister's (2000) three predictions derived from the female plasticity theory. In comparison to men, women do 
seem to demonstrate greater degrees of intraindividual variability (sexually), their sexuality appears to be more impacted by sociocultural variables (e.g. education, religion, peers/parents, culture), and they tend to exhibit a high degree of attitude-behavior inconsistency.

\section{Explanations and Controversy}

In addition to proposing the higher erotic plasticity of women, Baumeister (2000) has also sought to explain its existence. He first proposes that it may in part be attributable to the power differential between men and women. Men are physically stronger, more aggressive, and tend to hold greater sociopolitical and economic power than women. If one considers that male physical power is strongly linked to male reproductive patterns and goals (as proposed by biologists and evolutionary psychologists) and that male political power shapes the sexual interactions between genders which results in the cultural suppression of female sexuality (as proposed by feminists), it seems that women may become more socially malleable as an adaptation to male power. Secondly, Baumeister suggests that female malleability may be an intrinsic requirement of the female role in sex. If one considers that historically and crossculturally, women have had a gatekeeper role in regards to sex, meaning that women often start off by saying no to sex but then occasionally switch to a positive response and accept sexual advances. Clearly, a certain degree of flexibility is required for this action

to take place. Lastly, Baumeister suggests that female erotic plasticity may be a result of the sex drive differential between the genders (Baumeister, 2004). More specifically, if women do have a weaker sex drive, they may be more easily persuaded to accept substitutes or alternate forms of satisfaction resulting in higher erotic plasticity. More 
recently, Baumeister (2004) has settled on this third explanation of the milder sex drive of women as the most powerful explanation for the gender difference in erotic plasticity.

The theory of female erotic plasticity is not without controversy (Andersen, Cyranowski, \& Aarestad, 2000; Hyde \& Durik, 2000). Hyde and Durik (2000) criticize Baumeister primarily for dismissing other alternative explanations and favoring biological and evolutionary reasons for the existence of a gender difference in plasticity. They propose that the difference can be better explained by sociocultural factors and gender-role expectations. Andersen, Cyranowski, and Aarestad (2000) are not even persuaded that female sexuality is more influenced by contextual factors than male sexuality. They suggest that the reverse may also be true, that biology may be a more powerful determinant in female sexuality than in male sexuality, considering the greater reproductive investment sex potentially signals for women.

While there is a substantial amount of literature supporting the female erotic plasticity theory, clearly more research is needed. In an ongoing attempt to test the validity of the theory, it seems reasonable to focus on ethnic and cultural differences and sexuality, as this has been the least researched area. First, however, we need to review the literature on ethnicity and sexuality to determine what we know about ethnocultural differences in sexual attitudes and behavior, quite apart from female erotic plasticity. The following section will focus on ethnocultural groups primarily within North America.

\section{Ethnocultural Differences in Sexual Attitudes and Behaviors}

There is an abundance of literature that focuses on ethnicity and sexuality, however, the bulk of it focuses on preventive sexual practices among minority 
populations (Lewis, 2004). Very little of the research on the sexuality of ethnic minorities focuses on sexual attitudes and most research exploring the sexual behavior of ethnic minorities focuses on high risk-taking sexual behaviors. Generally, the literature examining the sexual attitudes and/or behaviors of ethnic minorities has also focused on the comparisons to the Caucasian majority. A minority of studies compare the sexual attitudes and/or behaviors of several ethnicities to each other. The following is a literature review of sexual attitudes and behavior as they differ by ethnicity. Results for men and women should be read in the context of the consistent finding among Caucasians that men generally report more liberal attitudes and more varied sexual experience than women.

\section{Sexual Attitudes}

Studies examining sexual attitudes tend to characterize attitudes on a conservative/liberal continuum (Leiblum, Wiegel, \& Brickle, 2004; Meston, Trapnell, \& Borris, 1998; Staples, 1978). Other research has concentrated on attitudes towards specific feelings or behaviors such as guilt about sex (Wyatt and Dunn, 1991), coercive and non-coercive sexual behaviors (Kennedy \& Gorzalka, 2002); childbearing and marriage (Amaro, 1988; East, 1998; Moore \& Erickson, 1985; South 1993); contraceptive use (Beckman, Harvey, \& Tiersky, 1996); homosexuality (Parks, Hughes, \& Mathews, 2004; Rosario, 2002); dating (Tang, 2000); and the importance of sexual practices (Cain, Johannesm Avis, Mohr, Schocken, Skurnick, \& Ory, 2003). All of the aforementioned constitute specific sexual attitudes.

Studies focused on the liberal/conservative continuum have found that ethnic minorities tend to have more conservative sexual attitudes than the Caucasian majority. 
Meston, Trapnell, and Gorzalka (1998) examined differences in sexual knowledge and attitudes between 702 Canadian and 346 Asian-Canadian undergraduates at a university in Canada. Asian-Canadians had more conservative sexual attitudes and significantly less sexual knowledge than individuals of European descent. Moreover, Leiblum, Wiegel, and Brickle's (2004) study of 235 Canadian and U.S. medical students found that Caucasians from the U.S., Canada, Western Europe and South Africa were the most liberal while individuals of Middle Eastern and Asian descent were found to be the most sexually conservative.

Interestingly, Rushton and Bogaert (1987) found that African Americans were less sexually restrained than Caucasians, indicating a greater degree of sexual liberalism. Supporting these findings from the above study, Laumann, Gagnon, Michael, and Michaels (1994), in their study of a representative national sample of 20,000 individuals, investigated three major normative orientations toward sexuality: traditional, relational, and recreational. Traditional orientation is based on the assumption that the primary purpose of sexual activity is to reproduce and may be viewed as a conservative orientation; relational orientation is based on the notion that sexual activity is a natural part of an intimate and loving relationship; and recreational orientation is based on the idea that pleasure is the main purpose of sexual activity (this orientation may be viewed more towards the liberal end of the continuum). Laumann et al. (1994) found that close to $50 \%$ of their African American, Caucasian, and Hispanic sample identified as having a relational orientation, with the exception of the African American males of whom only $25.4 \%$ identified as having a relational orientation with $42.2 \%$ reporting having a 
recreational orientation. These results seem to indicate that almost half of the sample falls around the middle of the conservative/liberal continuum, with the exception of African American males.

In terms of sex guilt, Abramson and Imai-Marquez (1982) found that JapaneseAmerican women reported higher levels of sex guilt than Caucasian-American women. Also supporting the notion that some minorities may experience higher levels of sex guilt, Laumann and colleagues (1994) found that Hispanic women reported the highest feelings of guilt towards masturbation, followed by Caucasians and African Americans respectively. Wyatt and Dunn (1991) also examined levels of sex guilt among 126 African American women and 122 Caucasians and found that African American women had higher levels of sex guilt than their White peers. Interestingly, Price and Miller (1984) found that Caucasians reported higher levels of guilt than their African American counterparts, specifically for having sexual fantasies.

Taking a different spin on studying sexual attitudes, Kennedy and Gorzalka (2002) investigated attitudes between Asian and non-Asian university students in Canada towards coercive and noncoercive sexual behaviors. The results of this study indicated that Asians presented more conservative attitudes towards sexual behaviors than nonAsians and were found to be more tolerant of rape myths and more accepting of sexual harassment.

In terms of attitudes towards marriage, South (1993) found support for ethnic differences. His sample from the National Survey of Families and Households consisted of 2,214 unmarried and non-cohabitating individuals aged 19 to 35 . Hispanics demonstrated the strongest desire for marriage in comparison to African Americans and 
non-Hispanic Whites. Also investigating attitudes towards marriage while adding the component of childbearing, East (1998) examined potential racial and ethnic differences among an ethnically diverse sample of adolescents aged 11 to 15. African Americans perceived the greatest likelihood of having a child without being married, desired the longest lapse of time between first sexual intercourse and first birth and desired the least amount of time between marriage and birth of first child; Asians reported the lowest desire for having children and most perceived themselves as having a low likelihood of having sex during adolescence; Hispanics reported the strongest desire to take on marital and parenting roles at a young age.

Moore and Erickson (1985) not only examined child bearing attitudes and attitudes towards marriage but also knowledge about and attitudes towards contraceptives. Of the 594 ethnically diverse participants (aged 16 to 25), Asians and Hispanics knew significantly less about birth control and possessed less sexual knowledge overall than their African American and Caucasian counterparts. Caucasians and Asians reported a higher optimum age for marriage and childbearing than did African Americans and Hispanics.

While the above study examined a general knowledge of contraceptives, Beckman, Harvey, and Tiersky (1996) specifically investigated attitudes towards condoms among 197 college students. African American subjects reported more positive attitudes towards condoms than other ethnic groups and were more likely to use condoms. Their positive outlook on condoms may have been related to their degree of contraceptive knowledge because African Americans were also found to know less about oral contraceptives and less likely to use them than their Caucasian counterparts. 
Attitudes towards homosexuality have also been considered an important component of sexual attitudes. A longitudinal study conducted by Rosario (2002) examining ethnic and racial differences in the coming out process for lesbian, gay, and bisexual youths found that African American youths reported less involvement in gayrelated social activities and reported being less comfortable with others knowing their sexual orientation. They also disclosed their sexual orientation to fewer people than did Caucasians and Latino youth. On the other hand, African Americans were found to have greater increases in positive attitudes toward homosexuality and in their sexual identity over time than did Caucasians.

In terms of attitudes towards the importance of sexual practices, Cain, Johannes, Avis, Mohr, Schocken, Skurnick, and Ory (2003) examined the sexual practices of 3,262 women of menopausal status aged 42 to 52 . Whereas rates of engaging in sex did not vary by ethnicity, Japanese-American and Chinese-American women reported sex as being les important to them than did Caucasians. African Americans reported sex as being more important than did Caucasians.

This review of the literature on ethnicity and sexual attitudes makes it abundantly clear that sexual attitudes do indeed differ by ethnicity, although the exact differences that exist are not as apparent or consistent as one might expect. For the most part, it appears that minorities tend to have sexual attitudes that are more conservative than those of Caucasians. While results on sex guilt are not completely clear, it does appear that ethnic minorities may exhibit greater degrees of sex guilt when compared to Caucasians. In regards to attitudes towards coercive sexual behaviors, ethnic minorities (specifically Asians) reported being more tolerant of these behaviors (generally considered a 
conservative stance) than did Caucasians. Hispanics have been found to report having the greatest desire for marriage and parenting roles, Asians tend to report the highest optimum age for marriage and childbearing, and African Americans report the most positive attitudes towards and the greatest knowledge about condoms. In terms of attitudes towards homosexuality, African Americans reported the least amount of involvement in gay-related social activities and reported being the least comfortable with others knowing that they were gay, however, they were also found to have the largest increases in positive attitude over time. Asians have been found to hold less permissive views towards dating when compared to Caucasians, and Asian women have been found to report sex as being less important to them than it is to Caucasian women. In summary, ethno-cultural differences do appear to exist when examining a myriad of sexual attitudes and the trend appears to be skewed towards the conservative end of the spectrum, although there are some conflicting results.

\section{Sexual Behaviors}

Many different types of sexual behaviors have been studied across ethnicities although a disproportionate number of studies have focused on high-risk practices with groups not representative of general ethnic populations (e.g., Soet, Dudleym \& Dilorio, 1999; VanOss Marin, Tscann, Gomez, and Kegeles, 1993). There are however, some studies outside of the high-risk domain. Research with minority groups has been conducted on sexual decision making (Quadagno, Sly, Harrison, Eberstein, \& Soler, 1998); type of sexual activity (Stokes, Vanable, \& McKirnan, 1996; Quandango et al., 1998); degree of sexual experience (Sabogal, Perez-Stable, Otero-Sabogal, \& Hiatt, 1995; Sutker \& Kilpatrick, 1973; Quadango et al. 1998); age of first intercourse (Regan, 
Durvasuls, Howell, Urenom, \& Rea, 2004; Upchurch, Aneshensel, \& Mudgal, 2001); masturbation practices (Shulmand \& Holmes, 2003); frequency of sexual behavior (Lynn, 2000); and occurrence of sexual fantasies (Price \& Miller, 1984).

A review of the high-risk sexual behavior literature is not directly relevant to the focus of this thesis so we will focus on non-health related studies. Suffice it to say that ethnic differences in safe sex practices have been found frequently. For example, VanOss Marin, Tscann, Gomez, and Kegeles (1993) found that Hispanic women report fewer sexual partners than other ethnic groups. In addition, Spanish-speaking Hispanic women reported lower condom use and poorer attitudes toward condoms than non-Hispanic women and were less likely to believe that they could avoid HIV. In another example, Soet, Dudleym and Dilorio (1999) found ethnic differences between African American and Caucasians in terms of safe sex behavior, with African American women reporting higher expectancies for condom use.

Moving away from the high-risk sexual behavior literature and focusing on other sexual behaviors, Quandango and colleagues (1998) found interesting differences in their sample of 547 African American, Caucasian, and Hispanic women. Hispanic women reported a much higher percentage of mutual decision making in regards to type of sexual activity. African American and Caucasian women did not differ in this aspect. Hispanic and Caucasian women reported engaging in oral sex twice as much as African American women and Hispanic women reported participating in anal sex three times more than African American and Caucasian women. Also examining ethnic differences and sexual behaviors but focusing on a gay and bisexual population, Stokes, Vanable, and McKirnan (1996) conducted structured face to face interviews with 515 African American and 
Caucasian men 18 to 30 years of age. African American participants reported fewer male sexual partners, more insertive anal sex with men, and were less likely to be recipients of oral sex. African American subjects perceived friends and neighbors to be less accepting of their homosexual behavior, but estimated a high prevalence of bisexual activity among men their age.

Laumann and colleagues (1994) found many ethnocultural differences when examining sexual practices across the United States among heterosexuals. In terms of oral sex, a higher percentage of Caucasian men reported engaging in active and receptive oral sex followed by Hispanics, Asians, and African Americans. Similarly a higher percentage of Caucasian women reported engaging in active and receptive oral sex followed by Hispanics and African Americans (no data was reported for the Asian women). On the matter of heterosexual anal sex, a higher percentage of Hispanic men reported engaging in anal sex followed by Caucasian, African American, and Asian men respectively. For women, a higher percentage of Caucasians reported engaging in anal sex followed by Hispanics and African Americans, again no data for Asian women was reported. In terms of monthly sexual frequency they found that African Americans reported having sex 6.4 times, Asians 5.9 times, Caucasians 6.6 times, and Hispanics 7.7 times.

Degree of sexual experience has also been found to be related to ethnicity. Sutker and Kilpatrick (1973) conducted a study consisting of 73 African American and Caucasian undergraduates. Females of both races were similar in sexual attitudes and behavior. However, data indicated that African American males were more sexually experienced than Caucasians, despite a similarity in sexual attitudes. Muram, Rosenthal, 
Tolley, and Peeler (1991) compared dating and sexual attitudes and practices of 83 African American and 70 Caucasian high school senior girls and also found that African Americans reported more sexual experience then their Caucasian counterparts. Also supporting the findings of that study, Laumann and colleagues (1994) found that $6 \%$ of African Americans surveyed reported having five or more sexual partners compared with only $2.7 \%$ of Caucasians, $2.5 \%$ of Hispanics, $2.4 \%$ of Native Americans, and $0 \%$ of Asians. Lynn (2000) also found that African American males reported a greater number of sexual partners and a greater frequency of sexual intercourse, although these results differed from the Laumann et al. study (1994) in which Hispanics reported the greatest frequency of sexual intercourse.

Sabogal, Perez-Stable, Otero-Sabogal, and Hiatt (1995) explored correlates of sexual behaviors in a sample of 1,343 female and 1,250 male Hispanic and non-Hispanic Whites 35 to 74 years of age. Hispanic men were more likely to start sexual intercourse at an earlier age and use condoms less frequently than Caucasians. Hispanic women had more children, used contraception less, had fewer lifetime sexual partners, and had fewer sexually transmitted diseases. Also exploring first sexual experiences, Regan, Durvasula, Howell, Urenom and Rea (2004) conducted a study investigating the age at which young adults experienced their first date, love, serious relationship, kiss, and sexual intercourse experience. All firsts typically occurred towards the end of high school, although first dates and kisses occurred earlier than falling in love or first intercourse. Asian American participants were less sexually and romantically experienced than African Americans, Latinos, and Caucasians, although no ethnicity differences in first romantic love experience were reported. 
Masturbation practices and their relationship to ethnicity have also been examined. Results from the Laumann et al. (1994) study indicated that $33.1 \%$ of Hispanic men reported not masturbating at all compared with $33.4 \%$ of Caucasian men, $38.7 \%$ of Asian men, and $60.3 \%$ of African American men. Among women, they found that $55.7 \%$ of Caucasians reported not masturbating compared with $65.5 \%$ of Hispanics, and $67.8 \%$ of African Americans (no data for Asian women was reported). In Shulman and Home's (2003) study of 96 women, European American women reported a higher frequency of masturbation than African Americans. A positive relationship between masturbating and positive body image was also found among the European American women but not among the African American women.

In the realm of sexual fantasies and their relationship to ethnicity, Price and Miller (1984) examined the prevalence of sexual fantasies among African Americans and Caucasians. Of the 128 undergraduates surveyed, $85 \%$ of all participants reported fantasizing during intercourse, although African Americans reported fantasizing more frequently during intercourse than did Caucasians. African American participants had fantasies including aggression, homosexual behavior, anal and oral sex, and interracial sex more than their Caucasian counterparts.

Of great relevance to ethnic differences and sexual behaviors, Dube and SavinWilliams (1999) explored the ways in which ethnicity influences sexual development among homosexual males. Participants consisted of 139 minority male youths. Results from this study indicated that differences across ethnic groups do exist in terms of disclosure of sexual identity to family members. Specifically, African Americans and Caucasians were found to have higher rates of disclosures to family members than were 
Asians and Hispanics. Further research on ethnocultural differences and same-gender sexual activity and homosexuality was included in the Laumann et al. (1994) study. Same gender sexual activity among men was highest for Caucasians followed by African Americans, Hispanics, and Asians. Of the Asian women surveyed, none reported having engaged in same-gender sexual activity although $4.7 \%$ of Caucasian women, $3.5 \%$ of Hispanic women, and 2.8\% of African American women did report engaging in such behavior. In regards to homosexuality, none of the Asian men or women surveyed identified themselves as gay or bisexual although $4.8 \%$ of Hispanics, $4.7 \%$ of Caucasians, and $2.1 \%$ of African Americans identified as being gay or bisexual.

In summary the above literature review indicates that sexual behavior does appear to vary by ethnicity. As with sexual attitudes, the differences are not clear-cut. The literature review also aligns with Baumeister's (2000) realization that gender differences in terms of culture and sexuality have been left largely unexplored. Hispanic women report partaking in sexual decision-making more so than other ethnic groups. Caucasians report the highest prevalence of oral sex, with Hispanic men reporting the highest prevalence of anal sex, and African American women reporting the lowest prevalence of masturbation. In terms of degree of sexual experience, African American men have been found to report the greatest number of sexual partners and Hispanic men report engaging in sexual activity at the earliest age. African Americans have been found to endorse sexual fantasies more so than their Caucasian counterparts and Hispanics have been found to report having sex the most frequently.

While research on ethnic differences is important, any study that investigates ethnocultural differences in attitudes and behavior in a North American context is well 
advised to consider the degree of acculturation of their sample. While ethnicity may be described as the cultural characteristics that join specific groups of individuals who may share nationality, tribal affiliation, religious faith, language, and traditional or cultural origins (Lopez, 1997), acculturation refers to the level to which the individual adheres to these constructs. Clearly, our literature review indicated that ethnic differences in sexual attitudes and behaviors do exist. This raises the real possibility that acculturative differences may exist as well, prompting a need to review the literature on sexuality and acculturation before proceeding to the aims of our study.

\section{Acculturation and Sexual Attitudes and Behaviors}

Acculturation has been described as the process of psychological and behavioral modification that individuals and groups experience as a result of long-term contact with another culture (Berry \& Sam, 1997; Zea, Asner-Self, Birman, Buki, Lydia, 2003). A few of the studies discussed previously on the sexual attitudes and behaviors of ethnic minorities also included an acculturation component, which will be discussed in this section. It is important to note that there is a scarcity of research on acculturation and its relationship to sexual attitudes and behaviors. Despite this paucity of research, most of the existing data supports the notion that acculturation may impact sexual attitudes and behaviors, although there is insufficient data to determine whether acculturation affects men and women differently.

The research on sexual attitudes and their relationship to acculturation has focused primarily on the conservative/liberal continuum characterization of attitudes. Results from existing studies indicate that more liberal sexual attitudes are associated 
with higher levels of acculturation to Western culture. For example, Amaro (1988) examined the sexual attitudes of 137 Mexican-American women ages 18 to 63 and found that women who expressed more liberal attitudes towards sex were also more acculturated to Western culture. Moreover, Meston, Trapnell, and Boris (1998) found that recent Asian immigrants attending a Canadian university were significantly more likely than Canadian-born or long-term resident students to hold conservative sexual attitudes on a number of dimensions. Because length of stay in a new culture is related to degree of acculturation it seems that these results may be accounted for by an acculturation differential. Further supporting these findings, Leiblum, Wiegel, and Brickle (2004) found a significant relationship between acculturation and sexual attitudes, with the more acculturated individuals having more liberal sexual attitudes.

Other sexual attitudes that have been addressed in the literature in relationship to acculturation include attitudes towards coercive sexual behavior (Kennedy \& Gorzalka, 2002); sex-roles (Phinney \& Flores, 2002); and childbearing (East, 1998). In terms of the impact of acculturation on sexual behaviors, sexual-decision making (Ahmadi, 2003); marital conflict (Flores, Tschann, VanOss, \& Pantoja, 2004); and sexual risk-taking behaviors (Sabogal, Perez-Stable, Otero-Sabogal, \& Hiatt, 1995; Upchurch et al., 2001; VanOss, Tsehann, Gomez, \& Kegeles, 1993) have been studied. Generally speaking, most of the literature lends support to the notion that acculturation influences sexuality in various ways.

Kennedy and Gorzalka (2002) found results that indicate more rigid sexual attitudes among men when examining the differences between Asian and non-Asian university students on attitudes toward coercive and non-coercive sexual behavior. They 
found that both Asian and non-Asian women were less conservative on almost all items than men, possibly indicating that their sexual attitudes may be less-conservative as a result of cultural influences. Further results from this study indicated that as length of residency in Canada increased, Asian respondents demonstrated decreases in tolerance for rape myths and sexual harassment, indicating a potential acculturation effect.

Examining the sex-role attitudes of 170 Hispanics aged 18-78 years from first, second, and third generation immigrants, Phinney and Flores (2002) found that being male, less educated, and of an earlier generation predicted having traditional sex-role attitudes. Being of an earlier generation is indicative of a lower degree of acculturation. It is important to note that being male predicted having traditional sex-role attitudes suggesting that perhaps men are more inclined to keep traditional sex-role attitudes despite varying degrees of acculturation in other areas. As proposed by Baumeister (2000), this may be a result of male sexual attitudes being defined early in childhood resulting in a low degree of erotic plasticity.

In regards to childbearing attitudes, East (1998) studied an ethnically diverse sample $(n=574)$ and found that Hispanics born in the U.S. desired a younger age for first birth and a perceived a greater likelihood that they would have a child before marriage than Hispanics born in Mexico. Moreover, as length of residency in the U.S. increased so did their perceived probability of having children before marriage. Similarly, girls born in Southeast Asia perceived a lower likelihood of having a child before marriage than girls of South East Asian descent born in the U.S. Being born in the U.S. and longer length of residency in the U.S, may indicate a higher degree of acculturation to Western culture, although it could also signal a difference in socio-economic status. With that in mind, the 
results discussed above indicate that acculturation may impact perceived probability of having children before marriage and of age for first birth.

Although all the literature reviewed here focuses on ethnic groups in North American, a European example is here presented partly to compensate for the general lack of data on sex and acculturation. Ahmadi (2003) conducted 29 interviews with Iranian immigrants (age 30 to 50) who had been residing in Sweden for at least 10 years. He noted that the Iranians in his sample were influenced by the Swedish culture and way of thinking, resulting in a shift in the immigrants' views about the nature of the relationship between couples and sexual decision making within the relationship. More specifically, female participants indicted that they had learned how to help themselves in their sexual relationships and to demand satisfaction for their sexual needs and attributed this change to their immigration to Sweden. Male participants stressed that their sexual views in regards to sexual equality between genders had also changed since their immigration to Sweden.

Again within the domain of marital relationships, Flores, Tschann, VanOss, and Pantoja (2004) conducted a study consisting of 151 Mexican American husbands and wives to examine the relationship between acculturation and multiple dimensions of marital conflict. Results indicated that more acculturated husbands and wives engaged in less avoidance of conflict and were more expressive of their feelings in an argument. Moreover, results indicated that more acculturated males reported more frequent conflict regarding sex, although the type of conflict was not specified.

In a younger population, Upchurch and colleagues (2001) obtained data via a longitudinal survey of stress and mental health with a representative sample of Los 
Angeles County youth. The results from 497 adolescents that self-identified as Hispanic or Latino indicated that teens living in families who are foreign born have significantly lower risk of having sex. This may be a function of acculturation, as foreign born generations are likely to be less acculturated than native-born generations. While the above study only included males, Jimenez, Potts, and Jimenez (2002) conducted a study with 290 Latina adolescents and also found that less acculturated adolescents were less likely to engage in sexual behavior.

In the case of safe-sex practices, VanOss, Tschann, Gomez, and Kegeles (1993) examined the condom-using practices of 398 English and Spanish-speaking Hispanics and 540 non-Hispanic Whites. They found that Spanish-speaking Hispanic women reported lower condom use than Caucasians. Because language is often used as an indication of acculturation level, it seems that this may be attributable to an acculturation effect. Similarly, Ford and Norris (1993) identified the sexual behavior of 711 lowincome urban Hispanics aged 15 to 24 and found that highly acculturated women were much more likely to have used condoms, to have had at least one sexual partner in the last year, to have non-Hispanic partners, and to participate in oral and anal sex. For men, high acculturation was positively associated with oral sex and having non-Hispanic partners.

Exploring several facets of sexual behavior, Sabogal, Perez-Stable, OteroSabogal, and Hiatt (1995) surveyed 1,343 female and 1,250 male Hispanic and nonHispanic Whites ages 35 to 74 . Hispanic men were more likely to start sexual intercourse at an earlier age and to use condoms less than Whites. Hispanic women had more children, used less contraception, had fewer lifetime sexual partners, and had fewer 
sexually transmitted diseases. Hispanic men with lower degrees of acculturation reported younger age at first intercourse and less use of condoms than highly acculturated Hispanic men. Highly acculturated Hispanic women reported higher numbers of lifetime sexual partners than their less-acculturated counterparts.

The little research that exists does appear to suggest that acculturation level is related to a number of facets of sexuality. Clearly, there is a need for research in this area as little has been done. Not surprisingly, there is an even greater paucity of research in terms of how acculturation may influence male and female sexuality differentially. The theory of female erotic plasticity proposed by Baumeister (2000) would predict acculturative influences to be greater among women, as their sexuality is thought to be more fluid and therefore more influenced by contextual variables than that of men. The empirical verdict, however, is still out on whether or not acculturation exercises different effects on men and women.

\section{Aims of the Study and Hypotheses}

There is a significant body of data that supports the idea that female sexuality is more malleable than male sexuality and thus more greatly influenced by external factors. Female sexuality appears to be more affected by culture than by biology, and evidence for this plasticity is found in the greater intra-individual variation in the sexual behavior of women, the higher impact of socio-cultural factors on women, and a lower attitudebehavior consistency among women.

As previously noted, very little of the literature that Baumeister (2000) uses to support his theory of female erotic plasticity is based on the comparison of female and male sexual attitudes across ethnic cultures. Although this would seem like a direct test of 
the impact of culture, the question becomes more complicated and intriguing in the context of ethnic groups living within a majority culture, because of the added complication of varying levels of acculturation.

If female sexual attitudes and behaviors are indeed more culturally influenced, as Baumeister (2000) suggests, one interesting question raised would be, does the dominant culture exert more influence on female than on male sexuality or are women more influenced by their culture of origin than are men? One might reasonably hypothesize that men, being the less malleable of the sexes, might have been more influenced by their culture of origin to which they were exposed early on, and more resilient to the effects of acculturation on sexual attitudes and behavior. Women, on the other hand, may differ less across cultures of origin in their sexual attitudes, because they are more open to later culturally homogenizing influences than are men. In contrast, since women have shown greater sexual attitude-behavior inconsistency, we would expect that the more liberal attitudes of the highly acculturated would not be necessarily borne out by their behavior. Hypotheses

Based on the theory of female erotic plasticity and existing literature regarding gender and ethnic differences in sexual attitudes and behavior, the hypotheses of this study are as follows:

1) Ethnic minority group individuals will report more conservative attitudes than their Caucasian counterparts

2) Women will report more conservative attitudes than men

3) Ethnic minority group individuals will report less sexual experience than their Caucasian counterparts 
4) Women will report less sexual experience than men

5) Sexual attitudes of ethnic minority women will vary more as function of acculturation than will those of ethnic minority men

6) Sexual experience of ethnic minority women will vary more as function of acculturation than will that of ethnic minority men

7) There will be a weaker relationship between sexual attitudes and sexual experience in women than in men. 


\section{CHAPTER 3}

\section{METHODOLOGY}

\section{Participants}

A total of 544 participants completed the protocol, and no student refused to participate after a detailed description of the sexual nature of the study was disclosed. Analyses, however, were limited to participants who were between the age of 18 and 29 and who had missing data on no more than $5 \%$ of items on any one of the measures used in this study. Also excluded from analyses were participants who identified with an ethnicity other than European American, African American, Asian American (Pacific Islander), or Latino. The final sample thus consisted of 498 participants; 188 men and 310 women.

Table 1 presents the demographic characteristics of the sample used in the analyses. Almost two-thirds of the sample was female and the majority of participants were between 18-20 years of age, and either freshmen or sophomores. Self-identified ethnicity was relatively representative of college populations in the American Southwest. In terms of religious affiliation, the majority of the sample self-identified as Christian or Catholic.

For the purpose of future hypothesis-testing analyses, a median- split of acculturation was conducted using the African American, Asian American, and Latino 
combined sample. Levels of acculturation were thus labeled as high $(N=132 ; M=$ $165.19, S D=15.01)$ and low $(N=146 ; M=136.44, S D=8.71)$, and these two acculturation groups were significantly different on level of acculturation $t(276)=-19.24$, $p<.001$.

\section{Materials}

\section{Socio-demographic questionnaire}

A brief socio-demographic questionnaire inquiring about age, gender, ethnicity, and relationship status was administered.

\section{General Ethnicity Questionnaire (GEQ)}

The General Ethnicity Questionnaire (GEQ; Tsai, Ying, \& Lee, 2001) permits independent assessment of different kinds of cultural orientation and was used to assess each participant's level of acculturation to American culture. Two identical versions of the measure exist. The two versions of the measure seek to obtain cultural orientations pertaining to the individual's culture of origin (i.e. Mexican, Chinese, etc.) as well as to American culture. Participants use scale ratings from $1=$ strongly disagree to $5=$ strongly agree to rate how much they agree with statements about their cultural orientation (e.g., "When I was growing up 1 was exposed to the culture with which I most closely identify"). For items that pertain to the participant's language proficiency, the scale ratings range from $1=$ very much to $5=$ not at all (e.g., "How fluently do you write English?"). The GEQ is comprised of 38 items. Internal reliability (Cronbach's alpha) for the scale (and the various versions) was high ( $\alpha=.92$ for the GEQ-American version;) and one-month test-retest reliability was $.62(\mathrm{SD}=.22)$. Standard indices of acculturation (age of arrival, generational status, and length of residency in the United States) as identified 
by Marin (1992) were positively correlated with higher scores on the GEQ and thus support the notion that the GEQ is a valid measure.

\section{Derogatis Sexual Functioning Inventory}

The Derogatis Sexual Functioning Inventory (DSFI; Derogatis \& Melisaratos, 1979 ) is a 254 item self-report inventory and was used to obtain information about the participants' sexual attitudes, experiences and general sexual functioning. The DSFI is composed of 10 subtests: Information, Experience, Drive, Attitudes, Psychological Symptoms, Affect, Gender Role Definition, Fantasy, Body Image, and Sexual Satisfaction. An overall DSFI score is compiled from scaled scores from each subtest. Higher scores on the subscales and the DSFI overall score indicate better functioning in that area. The DSFI has been found to have very good internal consistency and reliability. For the purpose of this study the entire DSFI was administered, but only the scores from the Experience Subscale and the Attitude Subscale were used to measure sexual behavior and sexual attitudes. The Experience subscale has been found to have a test-retest coefficient of .92 and an internal consistency coefficient of .97 . In our sample, the internal consistency coefficient was .96 . The Attitude subscale has been found to have a test-retest coefficient of .81 (for items designed to measure liberalism) and .86 (for items designed to measure conservatism) and an internal consistency coefficient of .92 (for items designed to measure liberalism) and .72 (for items designed to measure conservatism) (Derogatis \& Melisaratos, 1979). In our sample the internal consistency coefficient for items designed to measure liberalism was .79 and the internal consistency coefficient for items designed to measure conservatism was .81 . Factor analytic results have demonstrated that the internal structure of the DSFI conforms to the hypothesized 
primary domains of sexual behavior (So-Kum Tang, Duen-mun Lai, \& Chung, 1997) thus supporting the validity of this measure. The DSFI has also been found to be able to differentiate one clinical group from another (Derogatis \& Melisaratos, 1979).

Procedure

This study was approved by the Institutional Review Board of the University of Nevada, Las Vegas. Participants were recruited on a volunteer basis from the University of Las Vegas, Nevada subject pool and from various campus organizations. Each participant was administered a general demographic questionnaire, with instructions requesting that upon completion of this questionnaire they bring the questionnaire to the researcher who then gave each participant a packet containing the appropriate version of the GEQ (i.e., Latino/Hispanic, Asian, African American), as well as the DSFI. These instruments were presented in their original English versions. 


\section{CHAPTER 4}

\section{RESULTS}

\section{Overview of Analyses}

First, we present analyses that test 1) whether socio-demographic characteristics of participants were related to the independent variables of gender, ethnicity or acculturation level and 2) whether the order of the presentation of the questionnaires were related to scores on the dependent measures: sexual attitudes and sexual experience Second, we present the investigation of the degree to which the dependent measure data met the assumptions of Analysis of Variance (ANOVA). We then proceed to test our study hypotheses: that women would report more conservative sexual attitudes and less sexual experience than men; that ethnic minority individuals would report more conservative sexual attitudes and less sexual experience than European Americans; that the sexual attitudes and sexual experiences of ethnic minority women would vary more as function of acculturation than those of ethnic minority men; and that men would exhibit more attitude-behavior consistency than would women.

\section{Covariation}

Tests of significance were performed to determine 1) if the order of the presentation of the questionnaires was related to scores on the dependent measures and 
2) if demographic variables were associated significantly with the three independent variables; gender, ethnicity, and acculturation level.

There were three presentation orders for the DSFI Sexual Attitudes Scale (DSFISA), the General Ethnicity Questionnaire (GEQ), and the DSFI Sexual Experience Scale (DSFI-SE). There were no significant differences in scores on sexual experience or attitudes between any of the presentation orders.

Age was not related to ethnicity or acculturation, but it was related to gender. Men $(M=20.14, S D=2.48)$ were significantly older than women $(M=18.94, S D=1.60)$, $t(496)=6.57, p<.001$. Age was thus used as a covariate in subsequent analyses. Religion, when collapsed into three categories (Christian/Catholic, Other, and No Religion), was related to gender and ethnicity but not to acculturation level. Women endorsed being Christian/Catholic more than did men and men endorsed affiliating with other religions or no religion at all more than did women, $\lambda^{2}(2, \mathrm{~N}=498)=17.43, p<$ .01 . The majority religious affiliation in all ethnic groups was Catholicism/Christianity, however more Asian Americans endorsed other religious affiliations, while more European Americans and Hispanics claimed no religious affiliation at all, $\lambda^{2}(6, \mathrm{~N}=498)$ $=24.26, p<.001$. Since religion was a categorical variable not easily amenable to covariation and since over $70 \%$ of our sample identified as Catholic/Christian, we decided not to attempt to control for religion in subsequent analyses.

Characteristics of the Distribution of Dependent Variables

To investigate the degree to which the data met the assumptions of Analysis of Variance (ANOVA) the skew and kurtosis of the distribution of the dependent measures used in this study were examined. The distribution of the Sexual Experience Scale was 
negatively skewed $($ skew $=-1.11 ;$ kurtosis $=.18)$, as was the Sexual Attitudes Scale $($ skew $=-.53 ;$ kurtosis $=.63)$, although to a lesser degree. Square root, $\log (10)$, and Inverse transformations of the data were attempted to correct the negative skew of the distributions so as to meet the assumptions of ANOVA. . In addition, participants who fell 2 standard deviations above or below the mean were defined as outliers and were eliminated in an additional attempt to correct the skew of the distributions. None of theses transformations had a substantial effect on the normality of the distribution

Analyses were nonetheless conducted and compared using original data, transformed data, and data with outliers excluded. None of the attempted corrections altered the significance of results of subsequent hypothesis-testing analyses. Thus, to retain maximum power, original non-transformed data with outliers included was used in the analyses presented below.

Hypotheses Testing

Hypotheses \#1\&2-Women will report more conservative sexual attitudes and fewer sexual experiences than men.

Table 2 presents the means and standard deviations of sexual attitudes and experience by ethnicity and gender.

Results from an ANCOVA, including both ethnic minority group individuals and European Americans, with gender as the independent variable, age as a covariate and sexual attitudes as the dependent measure indicated that women reported significantly more conservative sexual attitudes $(M=17.57, S D=16.20)$ than men $(M=21.16, S D$ 
$=14.40), F(1,495)=4.12, \mathrm{p}<.05$ (see Table 3$)$. A second ANCOVA conducted on sexual experience suggested no gender differences (see Table 4).

Hypotheses \#3\&4-Ethnic minority groups will report more conservative sexual attitudes and fewer sexual experiences than European Americans.

The three ethnic minority groups (African American, Asian American, Latino) were collapsed so as to directly test our $3^{\text {rd }}$ and $4^{\text {th }}$ hypotheses. Results from an ANCOVA with ethnicity as the independent variable, age as a covariate and sexual attitudes as the dependent variable indicated that ethnic minority group participants reported significantly more conservative sexual attitudes $(M=17.34, S D=14.53)$ than their European American counterparts $(M=20.93, S D=16.73), F(4,493)=5.87, \mathrm{p}<.05$ (see Table 5). A second ANCOVA with sexual experience as the dependent variable indicated that European Americans reported significantly more sexual experiences $(M=$ $17.36, S D=5.90)$ than ethnic minority group participants $(M=13.38, S D=7.16), F$ $(4,493)=9.01, p<.001($ see Table 6$)$

Although we did not hypothesize specific group differences between ethnic groups, we decided to further investigate where the differences lay. Two separate ANCOVA's with ethnicity as the independent variable, and age as a covariate, were conducted for sexual attitudes and sexual experience, followed by post-hoc comparisons. There was a significant group difference for sexual attitudes, $F(4,493)=5.15, \mathrm{p}<.01$ (see Table 7). Post hoc analyses showed that both European Americans $(p<.001)$ and Hispanic Americans $(\mathrm{p}<.02)$ endorsed more liberal sexual attitudes than Asian Americans. There was also a significant group difference for sexual experiences, $F$ 
$(4,493)=5.18, \mathrm{p}<.01$ (see Table 8$).$ Post hoc analyses showed that European Americans reported more sexual experience than Asian Americans $(\mathrm{p}<.001)$.

Hypotheses \# 5\&6-Sexual attitudes and sexual experiences of ethnic minority women will vary more as function of acculturation than will those of ethnic minority men

Sexual attitudes and sexual experiences were examined using two 2 (gender) X 3 (ethnicity: African American, Asian American, Latino) X 2 (acculturation: high, low) ANCOVAs, with age as a covariate.

For sexual attitudes, main effects were found for gender, ethnicity, and acculturation level. There were no interaction effects found. In regard to gender, women reported significantly more conservative sexual attitudes $(M=15.09, S D=15.47)$ than men $(M=20.71, S D=12.30), F(1,265)=8.09, p<.001$. An ethnic group difference was also identified, $F(2,265)=4.58, p<.05$, and post hoc analyses (Tukey's test) indicated that African Americans $(M=19.40, S D=14.90)$ and Latinos $(M=20.65, S D=$ 14.72) endorsed significantly more liberal sexual attitudes than did Asian Americans ( $M$ $=14.31, S D=13.69), p<.05$. Participants with a high level of acculturation also endorsed significantly more liberal sexual attitudes $(M=20.11, S D=13.57)$ than participants with a low level of acculturation $(M=14.83, S D=14.95), F(1,265)=9.78$, $p<.01$. (see Table 9).

For sexual experience, only one main effect was found for acculturation level. Participants with a high level of acculturation endorsed significantly more sexual experiences $(M=16.59, S D=7.81)$ than participants with a low level of acculturation $(M$ 
$=14.29, S D=7.81), F(1,265)=4.48, p<.05$. No main effects were found for gender or ethnicity and there were no interaction effects (see Table 10).

Although acculturation was measured as a continuous variable, we used the median split to consider it a two-level dichotomous factor in the preceding ANCOVA's. To ensure that our results were not an artifact of the transformation of acculturation from a continuous to a dichotomous variable, we ran moderated multiple regressions using the continuous version of the acculturation variable and the product term of gender and acculturation to test for the hypothesized interaction effect. Moderated multiple regression uses a hierarchical entry of the predictor variables to determine if one predictor variable (in this case, gender) and a criterion variable (sexual attitudes or sexual experience) is influenced by a third, moderating variable (in this case, acculturation) (Nunnally \& Bernstein, 1994).

Table 11 presents the correlations between acculturation and our two dependent variables (sexual attitudes and sexual experience) in men and in women. Acculturation appeared to have a stronger positive association with sexual experience in women than in men and a stronger positive association with liberal sexual attitudes in men than in women.

Using sexual attitudes as the criterion variable, the gender variable was entered into the equation in the first step. Next, the acculturation variable was added. Finally, an interaction term computed as a cross-product of predictors in the previous step (gender X acculturation) was entered into the regression equation (see Table 12). Stage 1 of the moderated hierarchical regression used gender to predict sexual attitudes. Variance accounted for by this initial model was very low $\left(\mathrm{R}^{2}=.04\right)$, indicating that gender alone 
was not a good predictor of sexual attitudes in this sample. Stage 2 involved using both the hypothesized main predictor (gender) and a moderator (acculturation). The incremental increase in $r$-square for this model $\left(\mathrm{R}^{2}=.06\right)$ was significant. $F,(1,275)=$ $17.71, \mathrm{p}<.001$, indicating that the addition of acculturation increased the predictive power of the model, although still accounting for a small proportion of the variance. The final stage of the regression involved adding the interaction term (gender X acculturation) to the model. The incremental increase in $r$-square for this addition $\left(R^{2}=.00\right)$ was not significant, indicating that there is no gender $\mathrm{X}$ acculturation interaction in the prediction of sexual attitudes, providing no support for our hypothesis. Thus, whether acculturation was analyzed as a dichotomous or continuous variable, it did not have a mediating effect on gender in the prediction of sexual attitudes.

Using sexual experience as the criterion variable, the same statistical procedure was followed. Variance accounted for by gender alone was very low $\left(R^{2}=.01\right)$, indicating that gender alone is not a good predictor of sexual experiences in this sample. The addition of acculturation resulted in an increase in $r$-square for this model $\left(\mathrm{R}^{2}=.04\right)$ that was significant. $F,(1,275)=10.82, \mathrm{p}<.01$, indicating that acculturation increases the predictive power of the model, although still accounting for a very small proportion of the variance. The incremental increase in $\mathrm{r}$-square for the addition of the gender $\mathrm{X}$ acculturation product term $\left(\mathrm{R}^{2}=.01\right)$ was not significant, indicating that there is no gender $\mathrm{X}$ acculturation interaction in the prediction of sexual experience, providing no support for our hypothesis. So again, whether acculturation was analyzed as a dichotomous or continuous variable, it did not have a mediating effect on gender in the prediction of sexual experience (see Table 13). 
Hypothesis \#7- There will be a weaker relationship between sexual attitudes and sexual experience in women than in men.

Bivariate correlations indicated a significant positive correlation between sexual attitudes and experience for men $(r=.31, p<.01)$ as well as for women $(r=.45, p<.01)$. To determine whether or not there was a significant difference between our two independent r's, Fisher's z transformation was used. Results did not show a significant difference between our two correlations, thus indicating that the relationship between the sexual attitudes and sexual experience of men and women does not differ significantly ( $\mathrm{z}$ $=1.39, \mathrm{p}>.05)$. 


\section{CHATER 5}

\section{DISCUSSION}

In this study, women reported more conservative sexual attitudes than did men, and ethno-racial minority group participants, as a group, reported more conservative sexual attitudes and fewer sexual experiences than did European Americans. More specifically, European Americans and Hispanic Americans endorsed more liberal sexual attitudes than did Asian Americans while European Americans reported a greater variety of sexual experiences than did Asian Americans. Acculturation was found to be positively associated with liberality of sexual attitudes in that participants categorized as high on acculturation endorsed more liberal sexual attitudes than participants categorized as low. There was no relationship found between acculturation and sexual experiences in this sample. Further, no support was found for the hypothesized differential impact of acculturation on the sexual attitudes and experiences of men and women. Finally, men were not found to have a greater attitude-behavior consistency than women. A consideration of each of the findings follows.

\section{Gender Differences}

In most studies, women have been found to be more critical of promiscuity, premarital sex, extramarital sex, and various other sexual activities (Alexander \& Fisher, 2003; Eisenman \& Dantzker, 2006; Laumann et al., 1994; Meston, Trapnell, \& Gorzalka, 1998; Oliver \& Hyde, 1993; Sprecher, 1989; Wilson, 1975), indicating greater sexual 
conservatism among women than among men. Our findings that women report more conservative sexual attitudes than do men are thus quite consistent with the existing literature. Ever-growing support for this gender difference in sexual attitudes may be explained by evolutionary theory, which suggests that women may be less permissive about sex as a result of the different sexual strategies employed by the two genders (Eisenman \& Dantzker, 2006). Because women are likely to invest the most effort and time into their offspring they tend to be more selective than men when choosing a mate and employ mating strategies accordingly (Buss \& Schmitt, 1993). A more sociocultural perspective suggests that because women are socialized to be more relationship-oriented (Cejka \& Eagly, 1999), it seems probable they may also be expected to disapprove of sexual behaviors perceived as potentially threatening to the stability and longevity of relationships (Alexander \& Fisher, 2003).

In reference to sexual experience, the literature has indicated that men report more sexual experience (both in frequency and variety) than do women (Alexander \& Fisher, 2003; Hyde \& Oliver, 2000). More specifically, men report a greater number of sexual partners (Smith, 1992), a higher incidence of intercourse (Oliver \& Hyde, 1993) and masturbation (Hyde \& Oliver, 2000; Leitenberg, Detzer, Srebnik, 1993; Oliver \& Hyde, 1993), and an earlier age of first intercourse than do women (Oliver \& Hyde, 1993; Smith, 1992). The lack of gender differences in our sample stands in contrast to these findings. Barring a very recent and unlikely generational change in the sexual behavior of men and women whereby previous gender differences are starting to disappear, our findings may be most parsimoniously explained by the youth of our sample. Clearly, participants who are older are likely to have had more opportunity for sexual experience. 
Samples primarily consisting of first-year college students at the start of their sexual lives may not have accumulated sufficient experience for the gender difference to surface.

However, this explanation is not borne out by a number of studies finding gender differences in sexual experience with young college samples as well (e.g., Leitenberg, Detzer, Srebnik, 1993; Meston, Trapnell, \& Gorzalka, 1998).

An alternate explanation can be found in Alexander and Fisher's (2003) suggestion that the apparent gender difference in sexual experience may actually be smaller than is currently reported in the literature. They propose that the gender difference in reports of sexual behavior may be a result of a gender difference in the distortion of sexual behavior. Employing a bogus pipeline methodology, they found that women who believed they were connected to a lie detector test reported more sexual experience (closer to that of men) than did women who believed they were participating in anonymous survey research. Furthermore, other researchers have found that women use rough approximations when reporting lifetime sexual partners whereas men tend to enumerate (Brown \& Sinclair, 1999), and a larger proportion of women than men report underreporting sexual behavior to their partners (Rubin, 1999). All of these data raise the possibility that gender differences in self-reported sexual behavior may be influenced, if not completely determined by, gender differences in the willingness to report sexual behavior.

\section{Ethno-racial Differences}

Researchers examining whether or not sexual attitudes vary by ethnicity more often than not report that European Americans endorse more liberal sexual attitudes than do ethno-racial minority samples (Eisenman \& Dantzker, 2006; Meston, Trapnell, \& 
Gorzalka, 1998; Leiblum, Wiegel, \& Brickle, 2004). Our results were relatively consistent with this body of research, as our ethno-racial minority group combined sample endorsed more conservative sexual attitudes than our European American sample. However, analyses of specific ethno-racial groups showed that this difference was primarily accounted for by the difference between European Americans and Asian Americans. This finding may be explained by the sexual socialization of Asian Americans, which appears to be more conservative than the sexual socialization that occurs in mainstream culture (Kim, 2005).

Contrary to some of the existing empirical literature, we did not find a significant difference between European Americans and either Hispanic Americans or African Americans. Research on the sexual attitudes of Hispanic Americans has indicated higher levels of sexual conservatism across ethnic groups. For example, Lauman and colleagues (1994) found that Hispanic women reported the highest feelings of guilt towards masturbation, followed by European Americans and African Americans, respectively, indicating more conservative sexual attitudes among Hispanic Americans. In addition, Hispanic Americans have been found to endorse the strongest desire for marriage in comparison to African Americans and non-Hispanic Whites (East, 1998) another indication of conservative sexual attitudes. In regard to African American attitudes, a handful of research indicates that they may hold more liberal sexual attitudes than European Americans on certain issues such as the appropriate age of first intercourse and nonmarital childbearing (Smith \& Zabin, 1993; Zabin, Hirsch, Smith \& Hardy, 1984). Our results did not support these findings, although that may be attributable to the use of 
different measures of sexual attitudes. The DSFI-SA does not assess attitudes relevant to masturbation guilt, desire for marriage, childbearing, or timing of first intercourse.

In terms of sexual experience, the literature on ethnic differences is not as consistent as that on sexual attitudes. For example, some research has indicated that African Americans have more sexual experience than European Americans (Lauman et al., 1994; Lynn, 2000; Sutker \& Kilpatrick, 1973; Muran, Rosenthal, \& Tolley, 1991) and Hispanic Americans (Upchurch, Aneshensel, Sucoff, \& Levy-Storms, 1999), while other research has indicated that European Americans endorse more sexual experience than ethnic minority group participants (Shuman \& Holmes, 2003; VanOss, Marin et al., 1993).

When examining our entire sample, our research supports the latter findings. However, this again seems to be primarily accounted for by differences between European Americans and Asian Americans. The sexual socialization of Asian Americans may be the most conservative relative to mainstream American culture. Our results are consistent with data from the National Health and Social Life Survey (NHSLS) study (Lauman et al., 1994) in which Asian men endorsed less active and receptive oral sex and heterosexual anal sex than European Americans. Support is also found in Regan, Durvasuls, Howell, Urenom, and Rea's study (2004), in which, again, Asian Americans endorsed the least amount of sexual experience across ethnic groups. A recent study (Kim, 2005) indicated that Asian parents tend to communicate more sexually conservative messages to their children than the messages communicated in the media. Kim suggested that the emphasis on social propriety, the cultural taboo associated with parents discussing sex with their children, and the concern that sexually active girls will 
develop a bad reputation may contribute to the sexual socialization of Asian Americans. The Asian American undergraduates who participated in Kim's study reported that they viewed Asian culture as sexually restrictive and conservative. Asian Americans have also been found to have a high frequency of body image disturbances (Alexis, Templeton, Gandhi, \& Gorzalka, 2004; Barnett, Keel, \& Conoscenti, 2001; Koff, Benavage, \& Wong, 2001), which is related to frequency of sexual behavior (Faith \& Schare, 1993). This may indicate that mainstream cultural values about physical attractiveness may pose a particular problem for Asian Americans, a problem that may impact their sexual behavior over and above the effects of their culture-of-origin values.

In terms of Hispanic Americans, findings in the literature have been mixed. Some studies have found that Hispanic American women report fewer sexual partners than other ethno-racial groups (e.g., Van Oss Marin et al, 1993) while others have found, for example, that Hispanic American women report similar levels of engagement in oral sex to those of European Americans, in sharp contrast to much lower levels in African American women (Quadagno et al, 1998). Similar inconsistencies have been found among African American samples. For example some research has indicated that Hispanic women engage in anal sex three times more than African American (Quandango et al., 1998) and African Americans engage in the least amount of both active and receptive oral sex across all ethnic groups (Lauman et al., 1994), thus indicating a more restricted range of sexual experiences for African Americans comparative to other ethnoracial groups. On the other hand, a number of studies have indicated that African Americans have higher frequencies of sexual experience particularly when compared to European Americans (e.g., Muram, Rosenthal, Tolley, \& Peeler, 1991; Sutker \& 
Kilpatrick, 1973) and a higher number of lifetime sexual partners (Lauman et al., 1994; Lynn, 2000). It is important for cultural research on sexuality to distinguish between frequency of sexual experience and variety of sexual acts engaged in. Although these two dimensions of sexual experience are likely to be positively associated, the strength of their association may vary across ethno-racial groups.

\section{Acculturation Differences}

When analyzing the ethnic minority group sample only, we found results that were fairly consistent with the results from the entire sample. Men reported more liberal sexual attitudes than women and Asian Americans endorsed more conservative sexual attitudes than Hispanic/Latino and African American participants. However, we were particularly interested in the extent to which acculturation, rather than ethno-racial group identity alone predicted sexual attitudes and behavior. As hypothesized, the more acculturated half of our sample endorsed more liberal sexual attitudes and more varied sexual experiences. This finding is fairly consistent with existing literature. A number of studies have found that acculturation does appear to play a role in the development of more liberal sexual attitudes (Amaro, 1988; Meston, Trapnell, \& Gorzalka, 1998). Research on sexual experience and acculturation is sparser, but again the literature does indicate a positive association between sexual experience and acculturation (Ford \& Norris, 1993; Upchurch, Aneshensel, \& Mudgal, 2001; Jimenez, Potts, \& Jimenez, 2002).

Importantly, however, our main contention that acculturation would have a greater effect on the sexual attitudes and behavior of men than of women was not supported. Our hypothesis was intended as a direct test of Baumeister's (2000) female erotic plasticity theory which posits that later cultural influences have more of an impact 
on women than they do on men, whose sexual preferences appear to get more permanently instated early on in life. We did not find that the sexual attitudes and sexual experiences of ethnic minority women varied more as function of acculturation than those of ethnic minority men in any definitive way. We did find that there was a significant positive relationship between sexual experience and acculturation for women, but not for men, which lends limited support to our hypothesis. This modest finding is consistent with the results of Ford and Norris' (1993) study which also found that level of acculturation correlated positively with several sexual practices for women, but not for men. However, the interaction effect we predicted was simply not confirmed

Again, the most parsimonious explanation for our lack of findings in this regard is the age of our sample. These were very young individuals and it is entirely possible that the acculturation $\mathrm{X}$ gender interaction we had hypothesized would only surface with the accumulation of sexual experience and the time needed for sexual attitudes to evolve. Another potential explanation relating to the limitations of our sample lies in the fact that they were all college students and thus, by definition, highly acculturated. Although there was variation in levels of acculturation and our high-acculturation group was significantly different than our low-acculturation group, one could easily argue that ethno-racial minority students who get admitted to college are by definition a highly acculturated group. However, it is important to also consider that the lack of support for Baumeister's theory in our study may indicate some weaknesses in his contention.

A major criticism of Baumeister's (2000) theory lies in his use of extreme groups to support his theory (Hyde and Durik, 2000). He compares the most educated (advanced degrees) with the least educated (high school degree) (Finger, 1975; Lauman et al., 1994; 
Wilson, 1975) and the most religious (fundamentalist Christians) to the least religious (individuals who endorsed no religion at all) (Lauman et al., 1994). If this criticism is valid, it would most definitely have explanatory value for our results. As mentioned previously, our two groups were likely both on one end of the acculturation spectrum, as all participants were college students and spoke English fluently. In concert with this criticism of Baumeister's support for his theory, we may have found support for our hypothesis had we used a sample with widely divergent acculturation levels.

\section{Attiude-Behavior Consistency}

In reference to attitude-behavior consistency, the present study did not find support for Baumeister's (2000) assertion that attitude-behavior consistency is greater for men than for women, as we found no such gender difference in our sample. Baumeister specifically suggests that if female sexuality is indeed more malleable to situational and social forces, then women's behavior cannot easily be predicted by attitudes, particularly attitudes that are general and abstract. Women's attitudes may be formed during early upbringing but their behavior may be increasingly influenced by situational pressures. One more time, it is possible that our sample was too young to capture the attitudebehavior divergence that might arise with time and age. Because the men in our sample endorsed more liberal sexual attitudes than the women and both genders exhibited similar amounts of sexual experience, one might expect that as time progresses and sexual experience is accrued, increased amounts of male sexual experience will align with already liberal sexual attitudes but increased amounts of sexual experience among women will diverge from their self-reported conservative sexual attitudes, thus resulting in a lower level of attitude-behavior consistency. It is also possible that the DSFI-SA 
assesses attitudes that are much more specific than the ones referenced by Baumeister and is thus unable to catch more general shifts in attitudes.

Lastly and as previously referenced, it seems there might be a gender difference in distortion of sexual behavior self-report (Alexander \& Fisher, 2003; Brown \& Sinclair, 1999; Rubin, 1999). Women in our sample may thus have actually engaged in more sexual experience than they endorsed. If indeed women underreported sexual experience, the discrepancy between the sexual attitudes and experience of women may be much larger than is apparent from their self-report.

\section{Limitations and Future Research}

The interpretation of our findings requires the consideration of a number of limitations. While power may be an apparent limitation of the present study, this limitation cannot explain the small effect sizes found for the hypotheses that were indeed confirmed. A much more obvious limitation is the characteristics of the sample itself. We utilized a convenience sample that consisted mostly of college freshmen. This poses a limitation for a variety of reasons. First, although $75 \%$ of our sample did report having had intercourse, the variance in sexual experience was relatively limited, largely attributable to the youth of the sample. In addition, because we are dealing with an English-speaking, college sample, the variance in acculturation was restricted to the high end of the acculturation spectrum. Another limitation is the use of an acculturation measure with African Americans. Although they represent a sub-culture of American society, they differ significantly from Hispanic and Asian Americans to the extent that their culture of origin is more distal and that language differences are dialectical. Most African Americans have multiple generations behind them that are native born, with little 
practical connection to their culture of origin (as an unfortunate consequence of slavery). This may make traditional acculturation measures less valid with this population than with groups that have a more recent and traditional immigration history. Finally, we are also concerned about the impact of gender differences in self-report response biases. That limitation, however, is common to all studies using self-report to investigate different aspects of sexuality.

Baumeister's theory of female erotic plasticity draws its support from a voluminous research on myriad aspects of sexuality that predate his theory. It is important to design studies to directly test this theory so that it does not rest exclusively on the interpretation of studies with other aims. Our study did not support his theory specifically in regard to acculturation, but this must be interpreted in light of the characteristics of our sample. The only conclusion we can draw from our study is that evidence for greater female erotic plasticity in regard to acculturation may not surface in the beginning stages of individuals' sexual lives. Our study cannot address what happens later in life. Similar studies with larger, more variably acculturated, and older samples would go further toward testing Baumeister's theory.

On a concluding note, there is an overall paucity of research on ethnicity and sexuality. What little there is seems almost exclusively focused on high-risk sexual practices within ethnic minority populations. We thus have a dearth of data on statistically normal sexual attitudes and behaviors and their correlates within these groups (Lewis, 2004). This focus does a disservice to our understanding of sexuality and to the sexual health of minority groups, who are pathologized and marginalized by a literature that primarily examines their sexuality as it relates to the potential for the transmission of 
disease. In addition, the literature examining the sexual attitudes and/or behaviors of ethnic minorities typically focuses on comparisons to European Americans. Only a handful of studies compare the sexual attitudes and/or behaviors of several ethnicities to each other which has greater potential for enhancing our knowledge of the ways in which different cultures impact on sexuality. The present study adds to the small body of research on the eudaemonic sexual practices (sexual practices concerned with acquiring sexual pleasure in a moral context) of a multicultural sample, while offering between ethno-racial group comparisons. Hopefully, further studies of this nature will be conducted to elucidate ethno-racial minority sexuality in this country and lead to the development of culturally informed and gender-specific interventions for sexual difficulties. 


\section{REFERENCES}

Abramson, P.R., \& Imai-Marquez, J. (1982). The Japanese-American: A cross-cultural, cross-sectional study of sex guilt. Journal of Research in Personality, 16(2), $227-$ 237.

Adams, C. G. \& Turner, B. F. (1985). Reported change in sexuality from young adulthood to old age. Journal of Sex Research, 21, 126-141.

Ahmadi, N. (2003) Rocking Sexualities: Iranian Migrants' Views on Sexuality. Archives of Sexual Behavior, 32(4), 317-326.

Alexander, M.G., Fisher, T. D., (2003). Truth and Consequences: Using the Bogus Pipeline to Examine Sex Differences in Self-Reported Sexuality. Journal of Sex Research, (40)1, 27-35.

Amaro, H. (1988). Women in the Mexican-American Community: Religion, Culture, and Reproductive Attitudes and Experiences. Journal of Community Psychology, 16, 6-20.

Andersen, B.L., Cyranowski, J.M., \& Aarestad, S. (2000). Beyond artificial, sex-linked distinctions to conceptualize female sexuality: Comment on Baumeister. Psychological Bulletin, 126(3), 380-384.

Antonovsky, H. F., Shoham, I., Kavenocki, S., Modan, B. \& Lancet, M. (1978). Sexual attitude-behavior discrepancy among Israeli adolescent girls. Journal of Sex Research, 14, 260-272. 
Barry, H. \& Schlegel, A. (1984). Measurements of adolescent sexual behavior in the standard sample of societies. Ethnology, 23, 315-329.

Baumeister, R.F. (2000). Gender Differences in Erotic Plasticity: The Female Sex Drive as Socially Flexible and Responsive. Psychological Bulletin, 126(3), 347-374.

Baumeister, R.F. (2004). Gender and erotic plasticity: Sociocultural influences on the sex drive. Sexual and Relationship Therapy, 19(2), 133-139.

Beck, J. G., Bozman, A. W. \& Qualtrough, T. (1991). The experience of sexual desire: Psychological correlates in a college sample. Journal of Sex Research, 28, 443456.

Beckman, L.J., Harvey, S.M., \& Tiersky, L.A. (1996). Attitudes about condoms and condom use among college students. Journal of American College Health, 44(6), 243-250.

Bell, A. P. \& Weinberg, M. S. (1978). Homosexualities: A study of diversity among men and women. New York: Simon \& Schuster.

Bergin, A.E. (1983). Religiosity and Mental Health: A Critical Reevaluation and Metaanalysis. Professional Psychology: Research and Practice, 14, 170-184.

Brown, N. R., \& Sinclair, R. C. (1999). Estimating lifetime sexual partners: Men and women do it differently. The Journal of Sex Research, 36, 292-297.

Buss, D.M., \& Schmitt, D.P., (1993). Sexual Strategies Theory: An Evolutionary Perspective on Human Mating. Psychological Review, 100(2), 204-232.

Cain, V.S., Johannes, C.B., Avis, N.E., Mohr, B., Schocken, M., Skurnick, J., \& Ory, M. (2003). Sexual functioning and practices in multi-ethnic study of midlife women: Baseline results from SWAN. Journal of Sex Research, 40(3), 266-276. 
Cejka, M. A., \& Eagly, A. H. (1999). Gender-stereotypic images of occupations correspond to sex segregation of employment. Personality and Social Psychology Bulletin, 25, 413-423.

Christensen, H. T. \& Carpenter, G. R. (1962). Value-behavior discrepancies regarding premarital coitus in three Western cultures. American Sociological Review, 27, 66-74.

Croake, J. W. \& James, B. (1973). A four-year comparison of premarital sexual attitudes. Journal of Sex Research, 9, 91-96.

Cortez, D.E., Rogler, L.H., \& Malgady, R.G. (1994). Biculturaality among Puerto Rican Adults in the United States. American Journal of Community Psychology, 22(5), $707-721$

Derogatis, L.R., \& Melisaratos, N. (1979) The DSFI: A Multidimensional Measure of Sexual Functioning. Journal of Sex \& Marital Therapy, 5(3), 244-281.

Dixon, J. K. (1984). The commencement of bisexual activity in swinging married women over age thirty. Journal of Sex Research, 20, 71-90.

Dube, E.M., \& Savin-Williams, R.C., (1999). Sexual Identity Development among ethnic sexual-minority male youths. Developmental Psychology, 35(6), 1389-1398.

Earle, J. R. \& Perricone, P. J. (1986). Premarital sexuality: A ten-year study of attitudes and behavior on a small university campus. Journal of Sex Research, 22, 304-310.

East, P.L. (1998). Racial and ethnic differences in girls' sexual, marital, and birth expectations. Journal of Marriage \& the Family, 60(1), 150-162 
Eisenman, R., Dantzker, M. L., (2006). Gender and Ethnic Differences in Sexual Attitudes at a Hispanic-Serving University. Journal of General Psychology, $133(2), 153-162$.

Faith, M. S., \& Schare, M. L. (1993). The role of body image in sexually avoidant behavior. Archives of Sexual Behavior, 22 (4), 345-356.

Fang, B. (1976). Swinging: In retrospect. Journal of Sex Research, 12, 220-237.

Finger, F. W. (1975). Changes in sex practices and beliefs of male college students: Over 30 years. Journal of Sex Research, 11, 304-317.

Fisher, W. A., Byrne, D., \& White, L. A. (1983). Emotional barriers to contraception. In D. Byrne \& W. A. Fisher (Eds.), Adolescents, sex and contraception (pp. 207239). New York: McGraw-Hill.

Ford, K. \& Norris, A. E. (1993). Urban Hispanic adolescents and young adults: Relationship of acculturation to sexual behavior. Journal of Sex Research, 30, 316-323.

Flores, E., Tschann, J.M., VanOss Marin, B., \& Pantoja, P. (2004). Marital conflict and acculturation among Mexican American husbands and wives. Cultural Diversity \& Ethnic Minority Psychology, 10(1), 39-52

Gilbert, F.S., \& Gamache, M.P. (1984). The Sexual Opinion Survey: structure and use. Journal of Sex Research, 20(3), 293-209.

Golden, C. (1987). Diversity and variability in women's sexual identities. In Boston Lesbian Psychologies Collective (Eds. ), Lesbian psychologies: Explorations and challenges(pp. 19-34). Urbana: University of Illinois Press. 
Harrison, D. A., Bennett, W. H., Globetti, G. \& Alsikafi, M. (1974). Premarital sexual standards of rural youth. Journal of Sex Research, 10, 266-277.

Herold, E. S. \& Mewhinney, D. -M. K. (1993). Gender differences in casual sex and AIDS prevention: A survey of dating bars. Journal of Sex Research, 30, 36-42.

Hyde, J. S., \& Oliver, M. B. (2000). Gender difference in sexuality: Results from a metaanalysis. In C. B. Tavris \& J. W. White (Eds.), Sexuality, society, and feminism (pp. 57-77). Washington, DC: American Psychological Association.

Jimenez, J., Potts, M.K., \& Jimenez, D.R. (2002). Reproductive Attitudes \& Behavior Among Latina Adolescents. Journal of Ethnic \& Cultural Diversity in Social Work, 11(3-4), 221-249.

Kennedy, M.A., \& Gorzalka, B.B. (2002). Asian and non-Asian attitudes toward rape, sexual harassment, and sexuality. Sex Roles, 46(7-8), 227-238.

Kennedy, M.A., Templeton, L., Gandhi, A., \& Gorzalka, B.B. (2004). Asian Body Image Satisfaction: Ethnic \& Gender Differences across Chinese, Indo-Asian, \& European-Descent Students. The Journal of Treatment \& Prevention, 12(4), 321336.

Kim, J. L. (2005). Sexual socialization among Asian Americans: A multi-method examination of cultural influences. Dissertation Abstracts International: Section B: The Sciences and Engineering, 66(2-B), 1198.

Kinsey, A. C., Pomeroy, W. B. \& Martin, C. E. (1948). Sexual behavior in the human male. Philadelphia: Saunders.

Kinsey, A.C., Pomeroy, W.B., Martin, C.E., \& Gebhard, P.H. (1953). Sexual Behavior in the Human Female: Philadelphia: Saunders. 
Koff, E., Benavage, A., \& Wong, B. (2001).Body-image Attitudes \& Psychosocial Funtioing in Euro-Americans and Asian-American College Women. Psychological Reports, 88(3), 917-928.

Laumann, E. O., Gagnon, J. H., Michael, R. T. \& Michaels, S. (1994). The social organization of sexuality: Sexual practices in the United States. Chicago: University of Chicago Press.

Leiblum, S., Wiegel, M., \& Brickle, F. (2004). Sexual attitudes of US and Canadian medical students: the role of ethnicity, gender, religion, and acculturation. Sexual and Relationship Therapy, 18(4), 473-491.

Leitenberg, H., Detzer, M.J., \& Srebnik, D., (1993). Gender Differences in Masturbation and the Relation of Masturbation Experience in Preadolescence and/or Early Adolescence to Sexual Behavior and Sexual Adjustment in Young Adulthood. Archives of Sexual Behavior, 22(2), 87-98.

Lewis, L.J. (2004). Examining Sexual Health Discourses in a Racial/Ethnic Context. Archives of Sexual Behavior, 33(3), 223-234.

López, I.F.H. (1997) Retaining Race: LatCrit Theory and Mexican American Identity in Hernandez v. Texas. Retrieved from http://www.students.law.miami.edu/ fvaldes/latcrit/archives/harvard/haney.htm\# N_1_, September 14, 2004.

Lynn, R. (2000). Race differences in sexual behavior and their demographic implications. Population \& Environment: A Journal of Interdisciplinary Studies, 22(1), 73-81. McCabe, P. (1987). Desired and experienced levels of premarital affection and sexual intercourse during dating. Journal of Sex Research, 23, 23-33. 
McCauley, E. A. \& Ehrhardt, A. A. (1980). Sexual behavior in female transsexuals and lesbians. Journal of Sex Research, 16, 202-211.

Meston, C., Trapnell, P.D., \& Gorzalka, B.B. (1998). Ethnic, gender, and length-ofresidency influences on sexual knowledge and attitudes. Journal of Sex Research, 35(2), 176-188.

Miller, B. C. \& Moore, K. A. (1990). Adolescent sexual behavior, pregnancy, and parenting: Research through the 1980s. Journal of Marriage and the Family, 52, $1025-1044$.

Mirande, A. M. (1968). Reference group theory and adolescent sexual behavior. Journal of Marriage and the Family, 30, 572-577.

Moore, D.S., \& Erickson, P.I. (1985). Age, gender, and ethnic differences in sexual and contraceptive knowledge, attitudes, and behaviors. Family \& Community Health, $8(3), 38-51$.

Muram, D., Rosenthal, T.L., Tolley, E.A., \& Peeler, M.M. (1991). Race and personality traits affect high school senior girls' sexual reports. Journal of Sex Education \& Therapy, 17(4), 231-243.

Murphy, S. (1992). A delicate dance: Sexuality, celibacy, and relationships among Catholic clergy and religious. New York: Crossroad.

Newcomer, S. \& Udry, J. R. (1987). Parental marital status effects on adolescent sexual behavior. Journal of Marriage and the Family, 49, 235-240.

Nunally, J. C. and I. H. Bernstein (1994). Psychometric Theory, ( ${ }^{\text {rd }}$ ed.). New York: McGraw-Hill. 
Oliver, M. B., \& Hyde, J. S. (1993). Gender differences in sexuality: A meta-analysis. Psychological Bulletin, 114, 29-51.

O'Sullivan, L. F. \& Allgeier, E. R. (1998). Feigning sexual desire: Consenting to unwanted sexual activity in heterosexual dating relationships. Journal of Sex Research, 35, 234-243.

Phinney, J.S., \& Flores, J. (2002). “Unpacking” acculturation: Aspects of acculturation as predicators of traditional sex role attitudes. Journal of Cross-Cultural Psychology, 33(3), 320-331.

Price, J.H., \& Miller, P.A. (1984). Sexual fantasies of Black and White college students. Psychological Reports, 54(3), 1007-1014.

Quadagno, D., Sly, D.F., Harrison, D.F., Eberstein, I.W., \& Soler, H.R. (1998). Ethnic Differences in Sexual Decisions and Sexual Behavior. Archives of Sexual Behavior, 27, (1), 57-75.

Regan, P.C., Durvasula, R., Howell, L., Ureno, O., \& Rea, M. (2004). Gender, ethnicity, and the developmental timing of first sexual and romantic experiences. Social Behavior \& Personality, 32(7), 667-676.

Roebuck, J. \& McGee, M. G. (1977). Attitudes toward premarital sex and sexual behavior among Black high school girls. Journal of Sex Research, 13, 104-114.

Rosario, M., Meyer-Bahlburg, H. F. L., Hunter, J., Exner, T. M., Gwadz, M. \& Keller, A. M. (1996). The psychosexual development of urban lesbian, gay, and bisexual youths. Journal of Sex Research, 33, 113-126.

Rushton, J.P., \& Bogaert, A.F. (1987). Race differences in sexual behavior: Testing an evolutionary hypothesis. Journal of Research in Personality, 21(4), 529-551. 
Sabogal, F., Perez-Stable, E.J., Otero-Sabogal, R., \& Hiatt, R.A. (1995). Gender, ethnic, and acculturation differences in sexual behaviors: Hispanic and non-Hispanic White adults. Hispanic Journal of Beahvioral Sciences, 17(2), 139-159.

Sack, A. R., Keller, J. F. \& Hinkle, D. E. (1984). Premarital sexual intercourse: A test of the effects of peer group, religiosity, and sexual guilt. Journal of Sex Research, $20,168-185$.

Savin-Williams, R. C. (1990). Gay and lesbian youth: Expressions of identity. New York: Hemisphere.

Shilbey-Hyde, J., \& Durik, A.M. (2000). Gender differences in erotic plasticityevolutionary or sociocultural forces? Comment on Baumeister (2000). Psychological Bulletin, 126(3), 375-379.

Shulman, J.L., \& Home, S.G. (2003). The use of self-pleasure: Masturbation and body image among African American and women. Psychology of Women Quarterly, $27(3), 262-269$

Smith, E. A., \& Zabin, L. S. (1993). Marital and birth expectations of urban adolescents. Youth and Society, 25, 62-74.

Smith, T. (1992). Discrepancies between men and women in reporting number of sexual partners: A summary from four countries. Social Biology, 39, 203-211.

Soet, J.E., Dudleym, W.N., \& Dilorio, C. (1999). The effects of ethnicity and perceived power on women's sexual behavior. Psychology of Women Quarterly, 23(4), 707723. 
So-Kum Tang, C., Duen-mun Lai, F., \& Chung, T.K.H. (1997). Assessment of Sexual Functioning for Chinese College Students. Archives of Sexual Behavior, 26(1), 79-91.

South, S. (1993). Racial and Ethnic Differences in the Desire to Marry. Journal of Marriage and the Family, 55, 357-360.

Sprecher, S. (1989). Premarital Standards for Different Categories of Individuals. Journal of Sex Research, 26(2), 232-248.

Stokes, J.P., Vanable, P.A., \& McKirnan, D.J., (1996). Ethnic differences in sexual behavior, condom use and psychological variables among Black and White men who have sex with men. Journal of Sex Research, 33(4), 373-381.

Sutker, P.B., \& Kilpatrick, D.G. (1973). Personality, biographical, and racial correlates of sexual attitudes and behavior. Proceedings of the Annual Convention of American Psychological Association, 261-262.

Tang, S., \& Zuo., J. (2000). Dating Attitudes and Behaviors of American and Chinese College Students. The Social Science Journal, 37(1), 67-78

Thornton, A., \& Camburn, D. (1989). Religious Participation and Adolescent Sexual Behaviors and Attitudes. Journal of Marriage and the Family, 51, 641-653.

Upchurch, DM., Aneshensel, \& Mudgal, J. (2001). Sociocultural Contexts of Time to First Sex among Hispanic Adolescents. Journal of Marriage and Family, 63, $1158-1169$.

Upchurch, D.M., Aneshensel, C.S., Sucoff, C.A., Levy-Storms, L., (1999). Neighborhood and Family Contexts of Adolescent Sexual Activity. Journal of Marriage \& the Family, 61 (4), 920-933. 
VanOss Marin, B., Tschann, J.M., Gomez, C.A., \& Kegeles, S.M., (1993). Acculturation and gender differences in sexual attitudes and behaviors: Hispanic vs nonHispanic White unmarried adults. American Journal of Public Health, 83(12), $1759-1761$.

Weis, D., Rabinowitz, B. \& Ruckstuhl, M. F. (1992). Individual changes in sexual attitudes and bhavior within college-level human sexuality courses. Journal of Sex Research, 29, 43-59.

Whisman, V. (1996). Queer by choice. New York: Routledge.

White, L.A., Fisher, W.A., \& Kingma, R. (1977). Development and validation of a measure of affective orientation to erotica: The Sexual Opinion Survey. Paper presented at the meeting of the Midwestern Psychological Association, Chicago, IL.

Wilson, W. C. (1975). The distribution of selected sexual attitudes and behaviors among the adult population of the United States. Journal of Sex Research, 11, 46-64.

Wyatt, G.E., \& Dunn, K.M. (1991). Examining predictors of sex guilt in multiethnic samples of women. Archives of Sexual Behavior, 20(5), 471-485.

Zabin, L. S., Hirsch, M. B., Smith, E. A., \& Hardy, J. B. (1984). Adolescent sexual attitudes and behavior: Are they consistent? Family Planning Perspectives, 16, 181-185.

Zea, M.C., Asner-Self, K.K., Birman, D., Buki, \& Lydia, P. (2003). The Abbreviated Multidimensional Acculturation Scale: Empirical Validation with Two Latino/Latina Samples. Cultural Diversity and Ethnic Minority Psychology, 9, (2), 107-12. 
Table 1

Demographic Characteristics of Participants ( $N=498)$ [cont'd]

Characteristic $\quad \underline{N} \quad \%$

Gender

Female

310

62.25

Male

188

37.75

Age of Participant

$18-21$

435

87.35

$22-25$

48

9.64

26-29

15

3.01

Year of Study

Freshman

287

57.63

Sophomore

108

21.69

Junior

65

13.05

Senior

27

5.42

Graduate Student

11

2.21

Self-Identified Ethnicity

$\begin{array}{lcc}\text { African American } & 67 & 13.45 \\ \text { Asian American } & 132 & 26.51 \\ \text { European American } & 220 & 44.18 \\ \text { Latino } & 79 & 15.86\end{array}$


Table 1

Demographic Characteristics of Participants $(N=498)$ [cont'd]

\begin{tabular}{lcc}
\hline Characteristic & $\underline{N}$ & $\%$ \\
\hline Self-Identified Religion & & \\
Catholic/Christian & 360 & 72.29 \\
No Religion & 93 & 18.67 \\
Other Religion & 45 & 9.04 \\
\hline
\end{tabular}


Table 2

Means and Standard Deviations for Sexual Attitudes and Sexual Experience

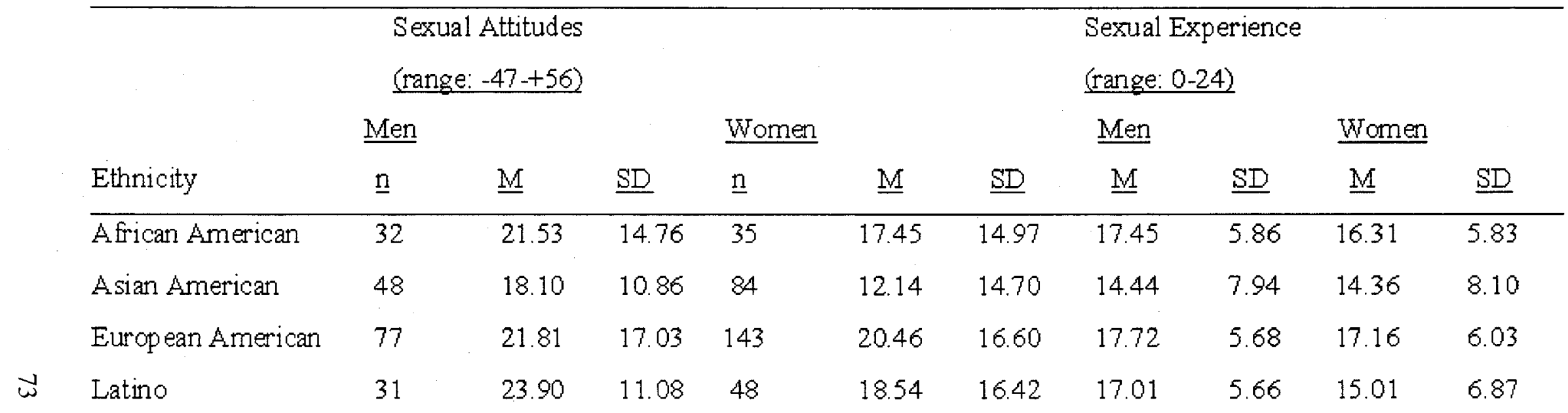

Note: Higher Scores on the Sexual Attitude Scale denote increasing liberalism and higher scores on the Sexual Experiences Scale denote more sexual experience. 
Table 3

Analysis of Covariance of Sexual Attitudes as a Function of Gender, With Age as a

\section{Covariate}

\begin{tabular}{lrrrrr}
\hline Source & $\underline{\mathrm{df}}$ & $\underline{\mathrm{SS}}$ & $\underline{\mathrm{MS}}$ & $\underline{\mathrm{F}}$ & $\underline{\omega^{2}}$ \\
\hline Covariate & 1 & 414.66 & 414.66 & 1.72 & .00 \\
Gender & 1 & 993.14 & 993.14 & $4.12^{*}$ & .00 \\
Error & 495 & 119425.37 & 241.26 & & \\
Total & 498 & 299718.09 & & & \\
\hline
\end{tabular}

$* p<.05$. 
Table 4

Analysis of Covariance of Sexual Experience as a Function of Gender, With Age as a

Covariate

\begin{tabular}{lrrrrr}
\hline Source & $\underline{\mathrm{df}}$ & $\underline{\mathrm{SS}}$ & $\underline{\mathrm{MS}}$ & $\underline{\mathrm{F}}$ & $\underline{\omega^{2}}$ \\
\hline Covariate & 1 & 903.80 & 903.798 & $20.97^{*}$ & .04 \\
Gender & 1 & .54 & .544 & .01 & .00 \\
Error & 495 & 21331.12 & 43.093 & & \\
Total & 498 & 153888.30 & & & \\
\hline${ }^{*} \mathrm{p}<.05$ & & & & &
\end{tabular}


Table 5

Analysis of Covariance of Sexual Attitudes as a Function of Ethnicity (Minority vs.

Majority), With Age as a Covariate

\begin{tabular}{lrrrrr}
\hline Source & $\underline{\mathrm{df}}$ & $\underline{\mathrm{SS}}$ & $\underline{\mathrm{MS}}$ & $\underline{\mathrm{F}}$ & $\underline{\omega^{2}}$ \\
\hline Covariate & 1 & 755.14 & 755.14 & 3.14 & .01 \\
Ethnicity & 3 & 1410.89 & 1410.89 & $5.87^{*}$ & .01 \\
Error & 495 & 119007.62 & 240.42 & & \\
Total & 498 & 299718.09 & & & \\
\hline
\end{tabular}

${ }^{*} \mathrm{p}<.05$. 
Table 6

Analysis of Covariance of Sexual Experiences as a Function of Ethnicity (Minority vs.

Majority), With Age as a Covariate

\begin{tabular}{lrrrrr}
\hline Source & $\underline{\mathrm{df}}$ & $\underline{\mathrm{SS}}$ & $\underline{\mathrm{MS}}$ & $\underline{\mathrm{F}}$ & $\underline{\omega^{2}}$ \\
\hline Covariate & 1 & 870.07 & 870.07 & $20.56^{* * *}$ & .04 \\
Ethnicity & 1 & 381.33 & 381.33 & $9.01 * *$ & .02 \\
Error & 495 & 20950.33 & 42.32 & & \\
Total & 498 & 153888.30 & & & \\
$* * * \mathrm{p}<.001, * *_{\mathrm{p}}<.01$. & & & &
\end{tabular}


Table 7

Analysis of Covariance of Sexual Attitudes as a Function of Ethnicity (African American

vs. Asian American, vs. Eureopean American vs. Latino), With Age as a Covariate

\begin{tabular}{lcrrll}
\hline Source & $\underline{\mathrm{df}}$ & $\underline{\mathrm{SS}}$ & $\underline{\mathrm{MS}}$ & $\underline{\mathrm{F}}$ & $\underline{\omega^{2}}$ \\
\hline Covariate & 1 & 647.30 & 647.30 & 2.73 & .01 \\
Ethnicity & 3 & 3661.99 & 1220.67 & $5.15^{* *}$ & .03 \\
Error & 493 & 116756.52 & 236.83 & & \\
Total & 498 & 299718.09 & & & \\
\hline
\end{tabular}

$* * \mathrm{p}<.01$. 
Table 8

Analysis of Covariance of Sexual Experiences as a Function of Ethnicity (African

American vs. Asian American, vs. European American, vs. Latino), With Age as a

Covariate

\begin{tabular}{lcrrrr}
\hline Source & $\underline{\mathrm{df}}$ & $\underline{\mathrm{SS}}$ & $\underline{\mathrm{MS}}$ & $\underline{\mathrm{F}}$ & $\underline{\omega^{2}}$ \\
\hline Covariate & 1 & 852.08 & 852.08 & $20.31^{* * *}$ & .04 \\
Ethnicity & 3 & 651.91 & 217.30 & $5.18^{* *}$ & .03 \\
Error & 493 & 20679.76 & 41.95 & & \\
Total & 498 & 153888.30 & & & \\
$* * * \mathrm{p}<.001, * * \mathrm{p}<.01$. & & & &
\end{tabular}


Table 9

Analysis of Covariance of Sexual Attitudes as a Function of Gender, Ethnicity (excluding

European Americans), and Acculturation, With Age as a Covariate

\begin{tabular}{lrrrrr}
\hline Source & $\underline{\mathrm{df}}$ & $\underline{\mathrm{SS}}$ & $\underline{\mathrm{MS}}$ & $\underline{\mathrm{F}}$ & $\underline{\omega^{2}}$ \\
\hline Covariate & 1 & 7.03 & 7.03 & .04 & .00 \\
Gender & 1 & 1578.01 & 1578.01 & $8.09^{* * *}$ & .03 \\
Ethnicity & 2 & 1788.74 & 894.37 & $4.58^{*}$ & .03 \\
Acculturation & 1 & 1907.30 & 1907.30 & $9.78^{* *}$ & .04 \\
Gender x Ethnicity & 2 & 51.12 & 25.56 & .13 & .00 \\
Gender x Acculturation Level & 1 & 294.60 & 294.60 & 1.51 & .01 \\
Ethnicity x Acculturation Level & 2 & 84.11 & 42.06 & .22 & .00 \\
Gender x Race x Acculturation Level & 2 & 97.61 & 48.80 & .25 & .00 \\
Error & 265 & 51698.80 & 195.09 & & \\
Total & 278 & 142027.16 & & & \\
\hline$* * *<.001, * 0$ & & & & & \\
\hline
\end{tabular}

$* * * \mathrm{p}<.001, * * \mathrm{p}<.01,{ }^{*} \mathrm{p}<.05$. 
Table 10

Analysis of Covariance of Sexual Experience as a Function of Gender, Ethnicity

(excluding European Americans), and Acculturation, With Age as a Covariate

\begin{tabular}{lrrrrr}
\hline Source & $\underline{\mathrm{df}}$ & $\underline{\mathrm{SS}}$ & $\underline{\mathrm{MS}}$ & $\underline{\mathrm{F}}$ & $\underline{\omega^{2}}$ \\
\hline Covariate & 1 & 148.67 & 148.67 & 3.03 & .01 \\
Gender & 1 & 16.10 & 16.10 & .33 & .00 \\
Ethnicity & 2 & 241.29 & 120.65 & 2.46 & .02 \\
Acculturation & 1 & 220.36 & 220.36 & $4.48^{*}$ & .02 \\
Gender x Ethnicity & 2 & 33.59 & 16.79 & .34 & .00 \\
Gender x Acculturation Level & 1 & 10.23 & 10.24 & .21 & .00 \\
Ethnicity x Acculturation Level & 2 & 149.36 & 74.68 & 1.52 & .01 \\
Gender x Race x Acculturation Level & 2 & 52.60 & 26.30 & .53 & .00 \\
Error & 265 & 13023.87 & 49.15 & & \\
Total & 278 & 79966.11 & & & \\
\hline *p $<.05$. & & & &
\end{tabular}


Table 11

Intercorrelations for Scores on Acculturation, Sexual Attitudes and Sexual Attitudes as a

Function of Gender

\begin{tabular}{llll} 
Measure & 1 & 2 & 3 \\
\hline 1. Acculturation & -- & $.18^{*}$ & $.24^{* *}$ \\
2. Sexual Attitudes & $.37^{* *}$ & -- & $.45^{* *}$ \\
3. Sexual Experience & .12 & $.31^{* *}$ & --
\end{tabular}

$* * \mathrm{p}<.01, * \underline{\mathrm{p}}<.05$

Note: Intecorrelations for men $(\mathrm{n}=111)$ are presented below the diagonal, and intercorrelations for women $(n=167)$ are presented above the diagonal. 
Table 12

Hierarchical Moderated Multiple Regression Analyses for Effects of Gender, $\underline{\text { Acculturation and their Interaction Term on Sexual Attitudes }}$

Possible Moderator Controlling for $\quad \mathrm{R}^{2} \quad$ Change in $\mathrm{R}^{2} \quad$ Error $\mathrm{df}$

Gender $\quad .04 \quad-\cdots$

$\begin{array}{lllll}\text { G X A } & \text { Gender, Acculturation } & .10 & .00 & 274\end{array}$

Note: All numerator $\mathrm{df}=1$. The alpha for the $F$ in the first model was $<.01$, and in the second model and third models it was $<.001$. 
Table 13

Hierarchical Moderated Multiple Regression Analyses for Effects of Gender, Acculturation and their Interaction term on Sexual Experience

\begin{tabular}{|c|c|c|c|c|}
\hline Possible Moderator & Controlling for & $\mathrm{R}^{2}$ & Change in $\mathrm{R}^{2}$ & Error df \\
\hline Gender & --------- & .01 & ------- & ----- \\
\hline Acculturation & Gender & .04 & .04 & 275 \\
\hline $\mathrm{G} \times \mathrm{A}$ & Gender, Acculturation & .05 & .01 & 274 \\
\hline
\end{tabular}


APPENDIX I

MEASURES 
Please use the following scale to indicate how much you agree with the following statements. Circle your response.

$\begin{array}{ccccc}1 & 2 & 3 & 4 & 5 \\ \text { Strongly Disagree } & \text { Disagree } & \text { Neutral } & \text { Agree } & \text { Strongly Agree }\end{array}$

\begin{tabular}{|c|c|}
\hline 1. I was raised in a way that was American. & 12345 \\
\hline 2. When I was growing up, I was exposed to American culture. & $\begin{array}{|lllll|}1 & 2 & 3 & 4 & 5\end{array}$ \\
\hline 3. Now I am exposed to American culture. & 123345 \\
\hline $\begin{array}{l}\text { 4. Compared to how much I negatively criticize other cultures, I criticize } \\
\text { American Culture less. }\end{array}$ & 123345 \\
\hline 5. I am embarrassed/ashamed of American culture. & 123445 \\
\hline 6. I am proud of American culture. & $1 \quad 2 \quad 3 \quad 4 \quad 5$ \\
\hline 7. American Culture has had a positive impact on my life. & $\begin{array}{lllll}1 & 2 & 3 & 4 & 5\end{array}$ \\
\hline 8. I believe that my children should read, write, and speak English. & 12345 \\
\hline 9. I have a strong belief that my children should have American names only. & 122345 \\
\hline 10. I go to places where people are American. & 122345 \\
\hline 11. I am familiar with American cultural practices and customs. & $\begin{array}{lllll}1 & 2 & 3 & 4 & 5\end{array}$ \\
\hline 12. I relate to my partner or spouse in a way that is American. & $\begin{array}{lllll}1 & 2 & 3 & 4 & 5\end{array}$ \\
\hline 13. I admire people who are American. & 122345 \\
\hline 14. I would prefer to live in an American community. & 12345 \\
\hline 15. I listen to American music. & 123345 \\
\hline 16. I perform American dance. & 123345 \\
\hline 17. I engage in American forms of recreation. & $\begin{array}{lllll}1 & 2 & 3 & 4 & 5\end{array}$ \\
\hline 18. I celebrate American holidays. & $\begin{array}{lllll}1 & 2 & 3 & 4 & 5\end{array}$ \\
\hline 19. At home I eat food American food. & 122345 \\
\hline 20. At restaurants I eat American food. & 12345 \\
\hline 21. When I was a child, my friends were American. & 122345 \\
\hline 22. Now, my friends are American. & 12345 \\
\hline 23. I wish to be accepted by Americans. & $\begin{array}{lllll}1 & 2 & 3 & 4 & 5\end{array}$ \\
\hline 24. The people that I date are American. & 12345 \\
\hline 25. Overall I am American. & $\begin{array}{lllll}1 & 2 & 3 & 4 & 5\end{array}$ \\
\hline
\end{tabular}


Please use the flowing scale to answer the following questions. Circle your response.

$\begin{array}{ccccc}1 & 2 & 3 & 4 & 5 \\ \text { Very much } & \text { Much } & \text { Somewhat } & \text { A little } & \text { Not at all }\end{array}$

\begin{tabular}{|c|c|}
\hline 26. How much do you speak English at home? & $1 \quad 23445$ \\
\hline 27. How much do you speak English at school? & $1 \quad 2 \quad 3 \quad 4 \quad 5$ \\
\hline 28. How much do you speak English at work? & 1223445 \\
\hline 29. How much do you speak English at prayer? & 12345 \\
\hline 30. How much do you speak English with friends? & 1223445 \\
\hline 31. How much do you view, read, or listen to English on TV? & $\begin{array}{lllll}1 & 2 & 3 & 4 & 5\end{array}$ \\
\hline 32. How much do you view, read, or listen to English in film? & 123345 \\
\hline 33. How much do you view, read, or listen to English on the radio? & 12345 \\
\hline 34. How much do you view, read, or listen to English in the literature? & 1223345 \\
\hline 35. How fluently do you speak English? & 123345 \\
\hline 36. How fluently do you read English? & 123345 \\
\hline 37. How fluently do you write English? & 122345 \\
\hline 38. How fluently do you understand English? & $1 \quad 2 \quad 3 \quad 4 \quad 5$ \\
\hline
\end{tabular}


Please use the following scale to indicate how much you agree with the following statements. Circle your response.

$\begin{array}{cllll}1 & 2 & 3 & 4 & 5 \\ \text { Strongly Disagree } & \text { Disagree } & \text { Neutral } & \text { Agree } & \text { Strongly Agree }\end{array}$

\begin{tabular}{|c|c|}
\hline 1. I was raised in way that was African American. & 12345 \\
\hline 2. When I was growing up, I was exposed to African American culture. & 12345 \\
\hline 3. Now, I am exposed to African American culture. & 12345 \\
\hline $\begin{array}{l}\text { 4. Compared to how much I negatively criticize other cultures, I criticize } \\
\text { African American culture less. }\end{array}$ & 12345 \\
\hline 5. I am embarrassed/ashamed of African American culture. & 12345 \\
\hline 6. I am proud of African American culture. & 12345 \\
\hline 7. African American culture has had a positive impact on my life. & 12345 \\
\hline 8. I believe that my children should read, write, and speak English & 12345 \\
\hline $\begin{array}{l}\text { 9. I have a strong belief that my children should have African American names } \\
\text { only. }\end{array}$ & 12345 \\
\hline 10. I go to places where people are American. & 12345 \\
\hline 11. I am familiar with African American cultural practices and customs. & 12345 \\
\hline 12. I relate to my partner or spouse in a way that is African American. & 12345 \\
\hline 13. I admire people who are African American. & 12345 \\
\hline $\begin{array}{l}\text { 14. I would prefer to live in an African American } \\
\text { community. }\end{array}$ & 12345 \\
\hline 15. I listen to African American music. & 12345 \\
\hline 16. I perform African American dance. & 12345 \\
\hline 17. I engage in African American forms of recreation. & 12345 \\
\hline 18. I celebrate African American holidays. & 12345 \\
\hline 19. At home, I eat African American food. & 12345 \\
\hline 20. At restaurants, I eat African American food. & 12345 \\
\hline 21. When I was a child, my friends were African American. & 12345 \\
\hline 22. Now, my friends are African American. & 12345 \\
\hline 23. I wish to be accepted by African Americans. & 12345 \\
\hline 24. The people I date are African American. & 12345 \\
\hline 25. Overall, I am African American. & 12345 \\
\hline
\end{tabular}


Please use the following scale to answer the following questions. Circle your response.

\begin{tabular}{|c|c|}
\hline 26. How much do you speak Black English at home? & 12345 \\
\hline 27. How much do you speak Black English at school? & 12345 \\
\hline 28. How much do you speak Black English at work? & 12345 \\
\hline 29. How much do you speak Black English at prayer? & 12345 \\
\hline 30. How much do you speak Black English with friends? & $12345^{\circ}$ \\
\hline 31. How much do you view, read, or listen to Black $T V$ ? & 12345 \\
\hline 32. How much do you view, read, or listen to Black films? & 12345 \\
\hline 33. How much do you view, read, or listen to Black radio? & 12345 \\
\hline 34. How much do you view, read, or listen to Black literature? & 12345 \\
\hline 35. How fluently do you speak Black English? & 12345 \\
\hline 36. How fluently do you read Black English? & 12345 \\
\hline 37. How fluently do you write Black English? & 12345 \\
\hline 38. How fluently do you understand Black English? & 12345 \\
\hline $\begin{array}{l}\text { 39. Are you bilingual? (please circle) } \\
\text { If yes, what languages? } \\
1 \text { ) } \\
\end{array}$ & Yes No \\
\hline
\end{tabular}


Please use the following scale to indicate how much you agree with the following statements. Circle your response.

$\begin{array}{cclll}1 & 2 & 3 & 4 & 5 \\ \text { Strongly Disagree } & \text { Disagree } & \text { Neutral } & \text { Agree } & \text { Strongly Agree }\end{array}$

\begin{tabular}{|c|c|}
\hline 1. I was raised in way that was Asian. & 12345 \\
\hline 2. When I was growing up, I was exposed to Asian culture. & 12345 \\
\hline 3. Now, 1 am exposed to Asian culture. & 12345 \\
\hline $\begin{array}{l}\text { 4. Compared to how much I negatively criticize other cultures, I } \\
\text { criticize Asian culture less. }\end{array}$ & 12345 \\
\hline 5. I am embarrassed/ashamed of Asian culture. & 12345 \\
\hline 6. I am proud of Asian culture. & 12345 \\
\hline 7. Asian culture has had a positive impact on my life. & 12345 \\
\hline 8. I believe that my children should read, write, and speak English & 12345 \\
\hline $\begin{array}{l}\text { 9. I have a strong belief that my children should have Asian names } \\
\text { only. }\end{array}$ & 12345 \\
\hline 10. I go to places where people are American. & 12345 \\
\hline 11. I am familiar with Asian cultural practices and customs. & 12345 \\
\hline 12. I relate to my partner or spouse in a way that is Asian. & 12345 \\
\hline 13. I admire people who are Asian. & 12345 \\
\hline 14. I would prefer to live in an Asian community. & 12345 \\
\hline 15. I listen to Asian music. & 12345 \\
\hline 16. I perform Asian dance. & 12345 \\
\hline 17. I engage in Asian forms of recreation. & 12345 \\
\hline 18. I celebrate Asian holidays. & 12345 \\
\hline 19. At home, I eat Asian food. & 12345 \\
\hline 20. At restaurants, I eat Asian food. & 12345 \\
\hline 21. When I was a child, my friends were Asian. & 12345 \\
\hline 22. Now, my friends are Asian. & 12345 \\
\hline 23. I wish to be accepted by Asians. & 12345 \\
\hline 24. The people I date are Asian. & 12345 \\
\hline 25. Overall, I am Asian. & 12345 \\
\hline
\end{tabular}


Please use the following scale to answer the following questions. Circle your response.

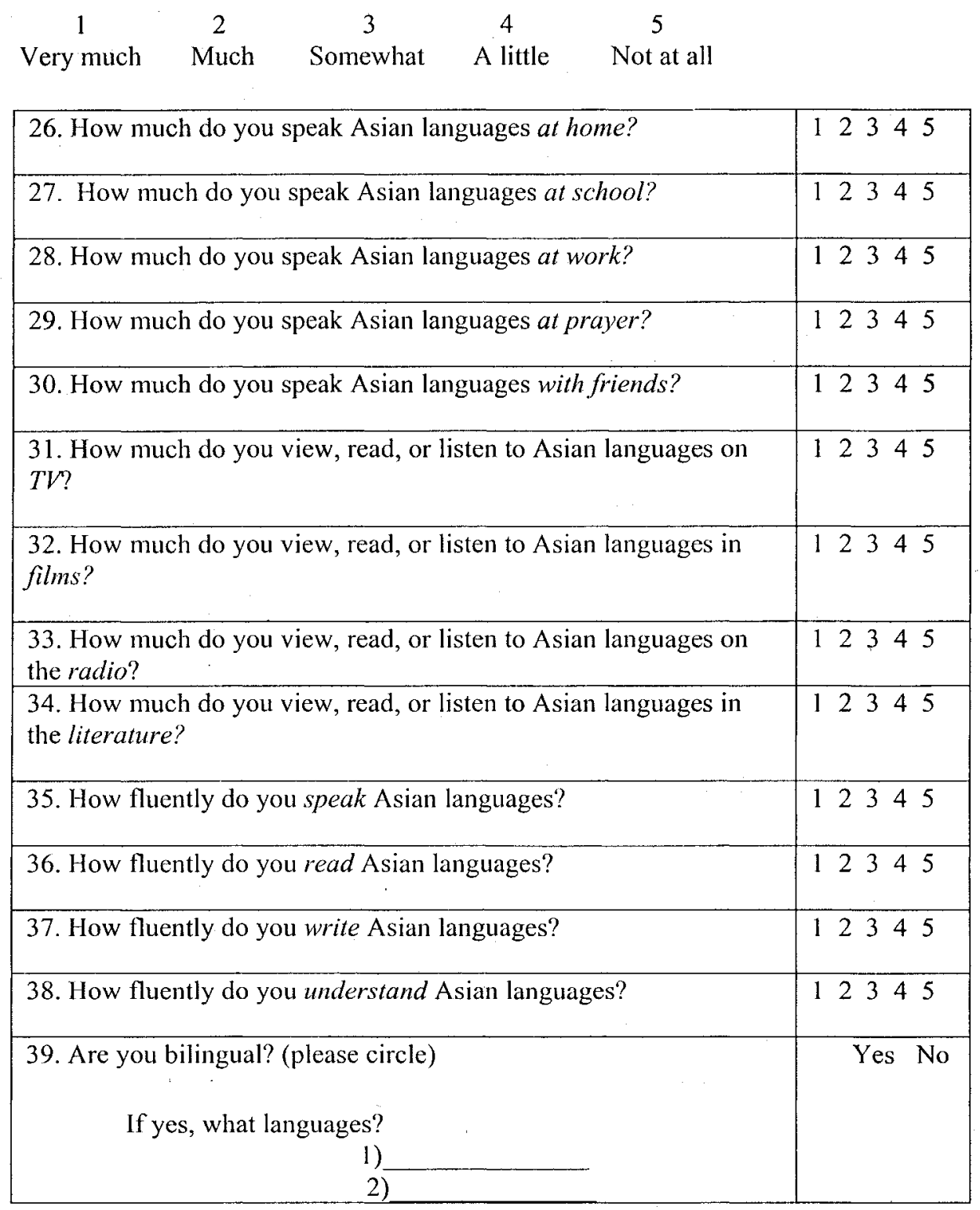


GEQ-His

Please use the following scale to indicate how much you agree with the following statements. Circle your response.

$\begin{array}{cllll}1 & 2 & 3 & 4 & 5 \\ \text { Strongly Disagree } & \text { Disagree } & \text { Neutral } & \text { Agree } & \text { Strongly Agree }\end{array}$

\begin{tabular}{|c|c|}
\hline 1. I was raised in way that was Hispanic/Latino(a). & 12345 \\
\hline $\begin{array}{l}\text { 2. When I was growing up, I was exposed to Hispanic/Latino(a) } \\
\text { culture. }\end{array}$ & 12345 \\
\hline 3. Now, I am exposed to Hispanic/Latino(a) culture. & 12345 \\
\hline $\begin{array}{l}\text { 4. Compared to how much I negatively criticize other cultures, I } \\
\text { criticize Hispanic/Latino(a) culture less. }\end{array}$ & 12345 \\
\hline 5. I am embarrassed/ashamed of Hispanic/Latino(a) culture. & 12345 \\
\hline 6. I am proud of Hispanic/Latino(a) culture. & 12345 \\
\hline 7. Hispanic/Latino(a) culture has had a positive impact on my life. & 12345 \\
\hline 8. I believe that my children should read, write, and speak English & 12345 \\
\hline $\begin{array}{l}\text { 9. I have a strong belief that my children should have } \\
\text { Hispanic/Latino(a) names only. }\end{array}$ & 12345 \\
\hline 10. I go to places where people are American. & 12345 \\
\hline $\begin{array}{l}\text { 11. I am familiar with Hispanic/Latino(a) cultural practices and } \\
\text { customs. }\end{array}$ & 12345 \\
\hline $\begin{array}{l}\text { 12. I relate to my partner or spouse in a way that is } \\
\text { Hispanic/Latino(a). }\end{array}$ & 12345 \\
\hline 13. I admire people who are Hispanic/Latino(a). & 12345 \\
\hline $\begin{array}{l}\text { 14. I would prefer to live in an Hispanic/Latino(a) } \\
\text { community. }\end{array}$ & 12345 \\
\hline 15. I listen to Hispanic/Latino(a) music. & 12345 \\
\hline 16. I perform Hispanic/Latino(a) dance. & 12345 \\
\hline 17. I engage in Hispanic/Latino(a) forms of recreation. & 12345 \\
\hline 18. I celebrate Hispanic/Latino(a) holidays. & 12345 \\
\hline 19. At home, I eat Hispanic/Latino(a) food. & 12345 \\
\hline 20. At restaurants, I eat Hispanic/Latino(a) food. & 12345 \\
\hline 21. When I was a child, my friends were Hispanic/Latino(a). & 12345 \\
\hline 22. Now, my friends are Hispanic/Latino(a). & 12345 \\
\hline 23. I wish to be accepted by Hispanic/Latino(a)s. & 12345 \\
\hline 24. The people I date are Hispanic/Latino(a). & 12345 \\
\hline 25. Overall, l am Hispanic/Latino(a). & 12345 \\
\hline
\end{tabular}


Please use the following scale to answer the following questions. Circle your response.

$\begin{array}{ccccc}1 & 2 & 3 & 4 & 5 \\ \text { Very much } & \text { Much } & \text { Somewhat } & \text { A little } & \text { Not at all }\end{array}$

\begin{tabular}{|c|c|}
\hline 26. How much do you speak Spanish at home? & 12345 \\
\hline 27. How much do you speak Spanish at school? & 12345 \\
\hline 28. How much do you speak Spanish languages at work? & 12345 \\
\hline 29. How much do you speak Spanish languages at prayer? & 12345 \\
\hline 30. How much do you speak Spanish languages with friends? & 12345 \\
\hline 31. How much do you view, read, or listen to Spanish on $T V$ ? & 12345 \\
\hline 32. How much do you view, read, or listen to Spanish in films? & 12345 \\
\hline $\begin{array}{l}\text { 33. How much do you view, read, or listen to Spanish on the } \\
\text { radio? }\end{array}$ & 12345 \\
\hline $\begin{array}{l}\text { 34. How much do you view, read, or listen to Spanish in the } \\
\text { literature? }\end{array}$ & 12345 \\
\hline 35. How fluently do you speak Spanish? & 12345 \\
\hline 36. How fluently do you read Spanish? & 12345 \\
\hline 37. How fluently do you write Spanish? & 12345 \\
\hline 38. How fluently do you understand Spanish? & 12345 \\
\hline $\begin{array}{l}\text { 39. Are you bilingual? (please circle) } \\
\text { If yes, what languages? } \\
1 \text { ) }\end{array}$ & Yes No \\
\hline
\end{tabular}




\section{S F I}

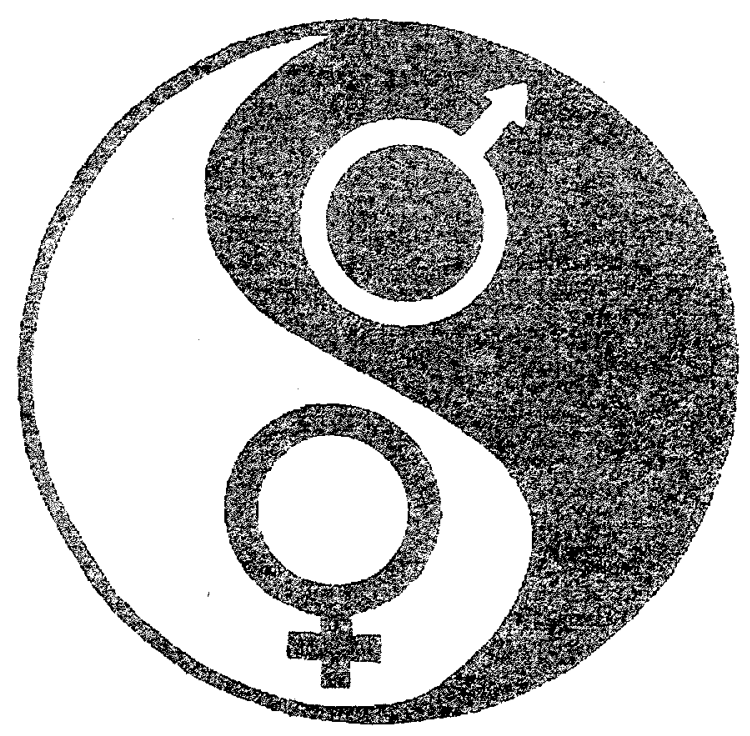

\section{DEROGATIS SEXUAL FUNCTIONING INVENTORY}

Reproduced with Permission of the Author. All rights reserved.

COPYRIGHT (C) 1975, 1978 BY LEONARD R. DEROGATIS, PH.D. 


\section{SECTION II}

Below is a list of sexual experiences that people have. We would to know which of these sexual behaviors you have experienced. Please indicate those experiences that you have personally had by placing a ( $\backslash \backslash)$ under the YES column for that experience. If you have not had the experience place your check $k$ under the NO column. In addition, if you have had the experience during the past two months please place an additional check under the column marked PAST 60 DAYS. Make your marks carefilly and do not skip any

items.

1. Men lying prone on female (clothed)

2. Stroking and petting your sexual partner's genitals.

3. Erotic embrace (clothed)

4. Intercourse-vaginal entry from rear

5. Having genitals caressed by your sexual partner

6. Mutual oral stimulation of genitals

7. Oral stimulation of your partner's genitals

8. Intercourse side-by-side

9. Kissing of sensitive (non-genital) areas of the body

10. Intercourse--sitting position

11. Masturbating alone

12. Male kissing female's nude breasts

13. Having your anal area caressed

14. Breast petting (clothed)

15. Caressing your partner's anal area

16. Intercourse-female superior position

17. Mutual petting of genitals to orgasm

18. Having your genitals orally stimulated

19. Mutual undressing of each other

20. Deep kissing

21. Intercourse - male superior position

22. Anal intercourse

23. Kissing on the lips

24. Breast petting (nude)

$\begin{array}{ll}\text { YES } & \text { NO } \\ {[]} & {[]} \\ {[]} & {[]} \\ {[]} & {[]} \\ {[]} & {[]} \\ {[]} & {[]} \\ {[]} & {[]} \\ {[]} & {[]} \\ {[]} & {[]} \\ {[]} & {[1]} \\ {[]} & {[]} \\ {[]} & {[]} \\ {[]} & {[]} \\ {[]} & {[]} \\ {[]} & {[]} \\ {[]} & {[]} \\ {[]} & {[]} \\ {[]} & {[]} \\ {[]} & {[]} \\ {[]} & {[]} \\ {[]} & {[]} \\ {[]} & {[]} \\ {[]} & {[]} \\ {[]} & {[]} \\ {[]} & {[]}\end{array}$

\section{PAST 60 DAYS}

[ ]

[ ]

[ ]

[ ]

[ ]

[ ]

[ ]

[ ]

[ ]

[ ]

[ ]

[ ]

[ ]

[ ]

[ ]

[ ]

[ ]

[ ]

[ ]

[ ]

[ ]

[ ]

[ ]

[ ] 


\section{SECTION IV}

Below are a series of statements about various aspects of sexual behavior. We would like to know to what extent you agree or disagree with each one. Please indicate how much you agree or disagree with each statement by placing the appropriate number from the alternatives below in the space alongside the statement. Please do not skip any statements and work quickly.

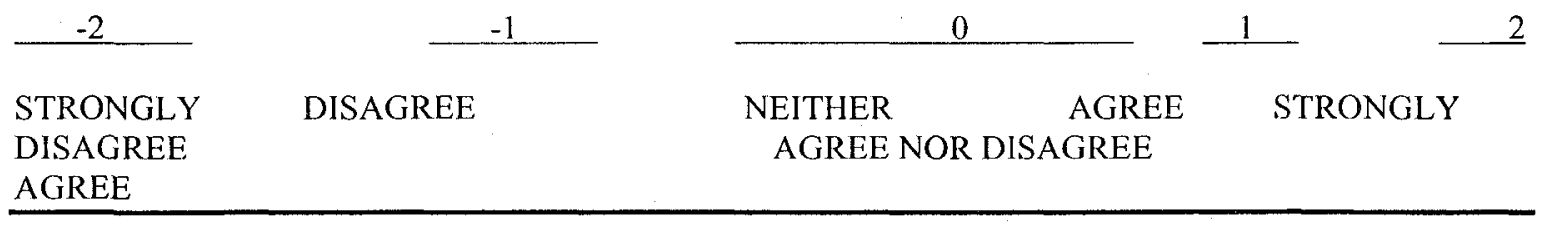

1. [ ] Premarital intercourse is beneficial to later marital adjustment

2. [ ] Homosexuality is perverse and unhealthy

3. [ ] Sex is morally right only when it is intended to produce children

4. [ ] Oral sex can be as pleasurable as intercourse

5. [ ] It is unnatural for the female to be the initiator in sexual relations

6. [ ] Masturbation is a perfectly normal, healthy sexual behavior

7. [ ] Extramarital sex inevitably leads to serious problems and great difficulty in the marriage

8. [ ] Women should never be consciously seductive but should wait upon the attentions of the man.

9. [ ] Viewing erotic films is enjoyable and stimulating behavior

10. [ ] Males and females should assume both assertive and passive roles during intercourse and foreplay

11. [ ] Most homosexuals are highly disturbed people and a danger to society

12. [ ] Any sexual behavior between two consenting adults should be viewed as normal

13. [ ] Morality should not be a consideration in sexual behavior

14. [ ] Dressing in various costumes to enhance sexual enjoyment should be viewed as creative sex

15. [ ] Books which contain passages explicitly describing sexual acts are usually just trash

16. [ ] Couples that have sex before marriage usually regret it later on

17. [ ] Wifeswapping is acceptable if all four partners agree

18. [ ] Males lose respect for females who allow them to have premarital intercourse

19. [ ] Mutual masturbation in a married couple is a poor substitute for intercourse

20. [ ] Prostitutes are immoral and degrading and have no place in society

21. [ ] Human genitals are somewhat disgusting to look at

22. [ ] Holding and touching my partner's body is exciting and thrilling

23. [ ] Group sex is a bizarre and disgusting idea

24. [ ] Extramarital sexual affairs can make people better marital partners

25. [ ] Couples should experiment with various positions of intercourse to enhance their sexual experiences

26. [ ] Masturbation fantasies are healthy forms of sexual release

27. [ ] Homosexuality is simply a question of sexual orientation and not good or bad, sick or healthy

28. [ ] Oral-genital sex is not within the range of normal sexuality

29. [ ] A picture of a nude woman can be a beautiful and exciting thing to look at

30. [ ] Pornography is perverse and disgusting in general and particularly harmful in the hands of young people 


\section{VITA}

Graduate College

University of Nevada, Las Vegas

Lorraine Benuto

Local Address:

2962 Juniper Hills Dr \#101

Las Vegas, NV 89142

Home Address:

352 Bella Vista Dellecker

Portola, CA 96122

Degrees:

Bachelor of Arts, Psychology, 2003

Dominican University of California

Special Honors and Awards:

Recipient of the GPSA grant at University of Nevada Las Vegas, 2005

Graduated Dominican University of California, Cum Laude, 2003

Recipient of the Presidential Scholarship at Dominican University of California ( $\$ 12,000$ per year), 2000-2003

Departmental Honors Dominican University of California, 2003

Inducted member of the Psi-Chi National Honor Society, 2003

Dean's List, 2003

Dominican University of California Honors Scholar, 2003

Dissertation/Thesis Title: Acculturation \& Sexuality: Investigating Gender Differences in

Erotic Plasticity

Dissertation/Thesis Committee:

Chairperson, Dr. Marta Meana, Ph.D.

Committee Member, Dr. Brad Donohue, Ph.D.

Committee Member, Dr. Murray Millar, Ph.D.

Graduate Faculty Representative, Kate Hausbeck, Ph.D. 